\title{
Clever Homunculus: Is There an Endogenous Act of Control in the Explicit Task-Cuing Procedure?
}

\author{
Gordon D. Logan \\ Vanderbilt University
}

\author{
Claus Bundesen \\ University of Copenhagen
}

\begin{abstract}
Does the explicit task-cuing procedure require an endogenous act of control? In 5 experiments, cues indicating which task to perform preceded targets by several stimulus onset asynchronies (SOAs). Two models were developed to account for changes in reaction time (RT) with SOA. Model 1 assumed an endogenous act of task switching for cue alternations but not for cue repetitions. Model 2 assumed no such act. In Experiments 1 and 2, the cue was masked or not masked. Masking interacted underadditively with repetition and alternation, consistent with Model 2 but not Model 1. In Experiments 3 and 4, 2 cues were used for each task. RT was slower for task repetition than for cue repetition and about the same as RT for task alternation, consistent with Model 2 but not Model 1. The results suggest that the explicit task-cuing procedure does not require an endogenous act of control.
\end{abstract}

Clever Hans was a remarkable horse who could add, subtract, multiply, and divide numbers, working with fractions as well as integers. His owner, von Osten, would ask him questions and Hans would tap out the answers with his hoof. An early experimental psychologist, Oskar Pfungst (1907, 1911), investigated Hans's ability and found that the horse responded to subtle visual cues from the person asking the questions. Hans was not so clever when he could not see the questioner or the questioner did not know the answer. The purpose of the present article is to report a similar investigation of the human homunculus - the agent responsible for executive control-as it appears in the explicit task-cuing procedure. We ask whether aspects of behavior observed in that procedure are due to a clever homunculus or to more mundane psychological processes.

Executive control refers to the processes by which the mind controls itself. Executive control processes include choosing among alternative strategies, enabling performance, monitoring performance, monitoring the consequences of performance, and disengaging strategies (Logan, 1985; Logan \& Gordon, 2001; Meyer \& Kieras, 1997; Norman \& Shallice, 1986). Recently, research has focused on the role of executive control processes in task switching, examining costs and benefits in performance as

This research was supported by Grants SBR-9808971 and BCS0133202 from the National Science Foundation and by funds from the University of Copenhagen. The Center for Visual Cognition is supported by a grant from the Danish Research Council for the Humanities. We are grateful to Julie Delheimer, Rachel Breinan, Katie Cook, Meredith Dickens, Maria Gumina, Matt Hamm, Julia High, Lynn Jacobson, Christian Lehman, and Jamie Rose for help with the experiments; to Julie Delheimer and Matt Hamm for help with the data analysis; to Mike Masson for help with the statistical analyses; and to Tom Palmeri and Nachshon Meiran for comments on this article.

Correspondence concerning this article should be addressed to Gordon D. Logan, Department of Psychology, Vanderbilt University, Nashville, Tennessee 37203, or to Claus Bundesen, Department of Psychology, University of Copenhagen, Njalsgade 90, DK-2300 Copenhagen S, Denmark. E-mail: gordon.logan@ vanderbilt.edu or claus.bundesen@psy.ku.dk subjects alternate between tasks or repeat the same task from trial to trial (Allport, Styles, \& Hsieh, 1994; Meiran, 1996; Rogers \& Monsell, 1995). Typically, reaction time (RT) is faster and accuracy is higher when subjects repeat the same task than when they alternate between tasks. This difference in performance between task repetition and alternation has become controversial. Some researchers interpret it as reflecting an endogenous act of control carried out by an executive process - the executive must reconfigure the system when the task alternates, and that takes time and produces errors (e.g., Rogers \& Monsell, 1995; Rubinstein, Meyer, \& Evans, 2001). Others interpret it as reflecting interference from previously active task sets-prior tasks and prior associations must be suppressed before the current task can be executed, and that takes time and produces errors (Allport et al., 1994; Allport \& Wylie, 2000; Wylie \& Allport, 2000). Still others interpret it as reflecting both types of processes (Goschke, 2000; Mayr \& Keele, 2000; Mayr \& Kliegl, 2000; Meiran, 1996, 2000).

The present article is concerned with the controversy over the endogenous act of control in the context of the explicit task-cuing procedure, which is one of several paradigms in which differences between task repetition and alternation have been observed (see Goschke, 2000; Mayr \& Kliegl, 2000; Meiran, 1996). We provide a formal model of the endogenous act of control and compare it to an alternative formal model that accounts for performance without assuming an endogenous act of control. We present five experiments that test critical predictions of several versions of the alternative models. Our novel contributions to theory are to model the time course of explicit cuing formally, which allows us to measure the durations of the critical processes, and to provide a new alternative to the endogenous act of control—one which suggests that the difference between task repetition and alternation is a benefit on repetition trials instead of a cost on alternation trials.

\section{The Explicit Task-Cuing Procedure}

In most experiments on task switching, subjects are shown a series of target stimuli that can be classified in several ways. In our first two experiments, for example, we present numbers like 3 or 
six that subjects can classify in terms of magnitude (greater or less than five), parity (odd or even), and form (digit or word). The earliest task-switching experiments compared blocks of trials in which subjects alternated between tasks (e.g., performing magnitude and parity judgments on successive stimuli) with blocks of trials in which subjects performed the same task throughout (e.g., performing magnitude judgments on each stimulus or parity judgments on each stimulus; see Jersild, 1927; Spector \& Biederman, 1976). This task alternation procedure is problematic because it confounds memory load with repetition and alternation-subjects must remember two tasks in the alternating blocks but only one in repeating blocks.

Rogers and Monsell (1995) introduced the alternating-runs procedure to remove the confounds in the alternating tasks procedure. They had subjects perform one task on two successive stimuli and another task on the next two successive stimuli (e.g., magnitude, magnitude, parity, parity, and so on; some experiments involved longer runs). With this procedure, repetition and alternation trials are performed in the same block of trials with the same memory load. The problem with the alternating-runs procedure is that the experimenter has little control over the point in time at which an endogenous act of control begins (if an act of control begins at all).

The explicit task-cuing procedure is intended to provide experimental control over the onset of the act of control (if there is one). Subjects are presented with a cue at the beginning of each trial that specifies which task is to be performed on the next stimulus (e.g., Mayr \& Kliegl, 2000; Meiran, 1996; Sudevan \& Taylor, 1987). In the present experiments, for example, we presented High-Low to cue magnitude judgments, Odd-Even to cue parity judgments, and Digit-Word to cue form judgments. Repetition and alternation trials are defined post hoc in terms of the sequence of cues: Repetition trials repeat the cue from the previous trial, whereas alternation trials present a different cue. The act of control (if there is one) begins when the cue has been encoded. The interval between the cue and the target (stimulus onset asynchrony; SOA) is manipulated to measure the time course of task switching. Typically, repetition trials are faster than alternation trials when the interval between the cue and target is short and the difference between repetition and alternation diminishes, sometimes to $0 \mathrm{~ms}$, as the interval increases. This time-course function reflects the duration of the processes involved in encoding the cue and switching task sets, but it reflects those durations indirectly. A model must be applied to the data to extract the durations of the processes. We propose models that assume an endogenous act of control and a model that assumes only a benefit of cue repetition.

\section{Modeling the Time-Course Function}

Many studies have investigated the time course of explicit cuing, but none have modeled the time-course function. Following Sperling and Weichselgartner's (1995) analysis of time-course functions in shifting attention, we model the time-course function in terms of the cumulative distribution of finishing times for processes that encode the cue and switch sets (see also Logan \& Bundesen, 1996). When the cue and the target are presented simultaneously - when SOA is 0 - RT includes cue-encoding time and task-switching time (if task switching occurs) as well as the time to process the target. When SOA is sufficiently long, the cue can be encoded and the task set switched before the target appears, so RT will reflect only target-processing time. As SOA increases from 0 , the probability that the cue is encoded will increase, as will the probability that the task set will be switched. RT will decrease as this probability increases, in accordance with the cumulative distributions of cue-encoding and task-switching times, until both processes are complete and RT reaches asymptote. We propose two basic models that differ in terms of their assumptions about an endogenous act of control in the explicit task-cuing procedure and in terms of their predictions about the effects of prolonging cue encoding on the difference between repetition and alternation trials. We test two versions of the model that assumes an act of control and we propose a third model that integrates the two models.

\section{Model 1: An Endogenous Act of Control}

The first model assumes that explicit cuing involves an endogenous act of control. When the cue is presented, it is encoded, which takes $\mu_{\mathrm{c}}$ ms on average. If the cue is the same as it was on the last trial (i.e., if it is a task-repetition trial), no further executive processes are required, and the target is processed in accord with the task set that was instantiated on the last trial. If the cue is different from the last trial (i.e., if it is a task-alternation trial), executive processes retrieve or derive the new task set and instantiate it, which takes $\mu_{\mathrm{s}} \mathrm{ms}$ on average. At that point, the target can be processed in accord with the new task set. If the cue and the target are presented simultaneously (i.e., if the SOA between them is $0 \mathrm{~ms}$ ), then mean RT on repetition trials is

$$
\mathrm{RT}_{\text {Repetition }}=\mathrm{RT}_{\text {Base }}+\mu_{\mathrm{c}},
$$

where $\mathrm{RT}_{\mathrm{B} \text { ase }}$ is the mean time required to process and respond to the target. The mean RT on alternation trials is

$$
\mathrm{RT}_{\text {Alternation }}=\mathrm{RT}_{\text {Base }}+\mu_{\mathrm{c}}+\mu_{\mathrm{s}} .
$$

Interaction between repetition versus alternation and SOA. Typically, the cue and the target are not presented simultaneously. The cue usually precedes the target by SOA ms, and some of the cue encoding and set switching can be done during this interval. If the SOA is long enough for cue encoding and set switching to be complete, then mean $\mathrm{RT}$ equals $\mathrm{RT}_{\mathrm{Base}}$ for both repetition and alternation trials. Thus, the model predicts an interaction between repetition and alternation and SOA such that the difference between repetition and alternation is $\mu_{\mathrm{s}} \mathrm{ms}$ at SOA $=0$ and approaches $0 \mathrm{~ms}$ at long SOAs.

At intermediate SOAs, RT will depend on the probability that cue encoding and set switching are finished (Sperling \& Weichselgartner, 1995). In order to estimate this probability, we must make some assumption about the distribution of cue-encoding and set-switching times. To simplify the mathematics and minimize the number of parameters to be estimated, we assumed that the distributions were exponential. Exponential distributions are completely characterized by a single (rate) parameter and have been used extensively to model the duration of processing stages in stochastic models of RT (e.g., Ashby, 1982; Ashby \& Townsend, 1980; Bundesen, 1990; Logan \& Gordon, 2001; Nosofsky \& Palmeri, 1997; Townsend \& Ashby, 1983). We examined several distributions in the family of generalized gamma distributions (see, e.g., McGill, 1963) and found they led to the same pattern of predicted results as the exponential, so we decided to use the simpler distribution. 
We assume that the time for cue encoding is distributed exponentially with a rate parameter of $1 / \mu_{\mathrm{c}}$. Thus, on repetition trials, mean $\mathrm{RT}$ will equal $\mathrm{RT}_{\text {Base }}$ if cue encoding is finished and $\mathrm{RT}_{\text {Base }}+\mu_{\mathrm{c}}$ if cue encoding is not finished. The probability that cue encoding is finished by SOA $\mathrm{ms}$ is equal to $F(\mathrm{SOA})=1-$ $\exp \left[-\mathrm{SOA} / \mu_{\mathrm{c}}\right]$ and the probability that cue encoding is not finished is equal to $1-F(\mathrm{SOA})=\exp \left[-\mathrm{SOA} / \mu_{\mathrm{c}}\right]$. Thus, mean $\mathrm{RT}$ equals $\mathrm{RT}_{\text {Base }}$ with probability $1-\exp \left[-\mathrm{SOA} / \mu_{\mathrm{c}}\right]$ and $\mathrm{RT}_{\mathrm{Base}}+$ $\mu_{\mathrm{c}}$ with probability $\exp \left[-\mathrm{SOA} / \mu_{\mathrm{c}}\right]$. Adding these together, Model 1 predicts that mean $\mathrm{RT}$ on repetition trials is

$$
\mathrm{RT}_{\text {Repetition }}=\mathrm{RT}_{\text {Base }}+\mu_{\mathrm{c}} \exp \left[-\mathrm{SOA} / \mu_{\mathrm{c}}\right] .
$$

On alternation trials, Model 1 assumes that cue-encoding time is distributed exponentially with rate parameter $1 / \mu_{\mathrm{c}}$ and that setswitching time is also distributed exponentially with rate parameter $1 / \mu_{\mathrm{s}}$. Thus, mean RT equals $\mathrm{RT}_{\mathrm{Base}}+\mu_{\mathrm{c}}+\mu_{\mathrm{s}}$ if cue encoding is not complete. This occurs with probability $\exp \left[-\mathrm{SOA} / \mu_{\mathrm{c}}\right]$. Mean RT equals $\mathrm{RT}_{\mathrm{Base}}+\mu_{\mathrm{s}}$ if cue encoding is complete but set switching is not complete. This occurs with probability

$$
\frac{1 / \mu_{\mathrm{c}}}{1 / \mu_{\mathrm{c}}-1 / \mu_{\mathrm{s}}}\left(\exp \left[-\mathrm{SOA} / \mu_{\mathrm{s}}\right]-\exp \left[-\mathrm{SOA} / \mu_{\mathrm{c}}\right]\right) .^{1}
$$

Finally, if cue encoding and set switching are complete, then mean $\mathrm{RT}$ equals $\mathrm{RT}_{\text {Base }}$. This occurs with probability

$1-\exp \left[-\mathrm{SOA} / \mu_{\mathrm{c}}\right]-\frac{1 / \mu_{\mathrm{c}}}{1 / \mu_{\mathrm{c}}-1 / \mu_{\mathrm{s}}}\left(\exp \left[-\mathrm{SOA} / \mu_{\mathrm{s}}\right]\right.$

$$
\left.-\exp \left[-\mathrm{SOA} / \mu_{\mathrm{c}}\right]\right)
$$

Putting these together, Model 1 predicts that mean RT on alternation trials is

$$
\begin{aligned}
& \mathrm{RT}_{\text {Alternation }}=\mathrm{RT}_{\text {Base }}+\exp \left[-\mathrm{SOA} / \mu_{\mathrm{c}}\right] \cdot\left(\mu_{\mathrm{c}}+\mu_{\mathrm{s}}\right) \\
& +\frac{1 / \mu_{\mathrm{c}}}{1 / \mu_{\mathrm{c}}-1 / \mu_{\mathrm{s}}}\left(\exp \left[-\mathrm{SOA} / \mu_{\mathrm{s}}\right]\right. \\
& \left.\quad-\exp \left[-\mathrm{SOA} / \mu_{\mathrm{c}}\right]\right) \cdot \mu_{\mathrm{s}} .
\end{aligned}
$$

Model 1 predicts that the difference in mean RT between alternation and repetition trials is

$$
\begin{aligned}
\mathrm{RT}_{\text {Alternation }}-\mathrm{RT}_{\text {Repetition }} & =\mu_{\mathrm{s}} \cdot\left(\frac{1 / \mu_{\mathrm{c}}}{1 / \mu_{\mathrm{c}}-1 / \mu_{\mathrm{s}}} \exp \left[-\mathrm{SOA} / \mu_{\mathrm{s}}\right]\right. \\
& \left.-\frac{1 / \mu_{\mathrm{s}}}{1 / \mu_{\mathrm{c}}-1 / \mu_{\mathrm{s}}} \exp \left[-\mathrm{SOA} / \mu_{\mathrm{c}}\right]\right)
\end{aligned}
$$

If $\mathrm{SOA}=0$, this difference equals the mean set-switching time, $\mu_{\mathrm{s}}$, independent of cue encoding time.

Interaction between repetition versus alternation and prolongation of cue-encoding time. The result in Equation 3 reflects the assumption that set switching is an "inserted Donderian processing stage" that intervenes between cue encoding and target processing (Rogers \& Monsell, 1995; Rubinstein et al., 2001). Set switching necessarily follows cue encoding. It occurs only if the current cue is different from the previous one, and that cannot be determined until the current cue is encoded. Thus, Model 1 predicts that factors that selectively influence cue-encoding time will not affect set-switching time and will not interact with repetition versus alternation at $\mathrm{SOA}=0$.

The first two experiments prolonged cue-encoding time by masking the cue, replacing five randomly chosen characters in the cue display with \# signs. We tested the hypothesis in Equation 3 in three related ways. The first involved fitting Model 1 to the data and examining estimates of $\mu_{\mathrm{s}}$. We fit Model 1 to the data in two ways. In the constrained fits, we forced $\mu_{\mathrm{s}}$ to take the same value whether or not the cue was masked. In the unconstrained fits, we allowed $\mu_{\mathrm{s}}$ to take different values when the cue was masked and when it was not masked. Model 1 predicts that $\mu_{\mathrm{s}}$ should have the same value whether or not the cue is masked in the unconstrained fits, and it predicts no significant improvement in the goodness of fit from the extra free parameter in the unconstrained fits.

The second way we tested the prediction did not involve fitting the model directly. We calculated the interaction contrast between repetition versus alternation and cue masked versus not masked at $\mathrm{SOA}=0$ (i.e., $\mathrm{RT}_{\text {Mask-Alternation }}-\mathrm{RT}_{\text {Mask-Repetition }}$ $\mathrm{RT}_{\text {No-Mask-Alternation }}+\mathrm{RT}_{\text {No-Mask-Repetition }}$ ). Equation 3 clearly predicts a null interaction when SOA $=0$ because the difference between repetition and alternation RT equals $\mu_{\mathrm{s}}$ exactly. The third test of the prediction involved calculating the interaction contrast between repetition versus alternation and cue masked versus not masked averaged over SOA. Intuition might suggest that the additivity would prevail at longer SOAs as the difference between repetition and alternation gets progressively smaller. However, a formal analysis of the interaction, presented in Appendix A, reveals that Model 1 predicts a positive (overadditive) interaction at SOAs greater than $0 .^{2}$ Thus, a negative (underadditive) interaction, averaged over SOA, would falsify Model 1 .

\section{Model 2: Encoding Benefit From Cue Repetition}

Model 2 exploits a peculiar feature that distinguishes the explicit task-cuing procedure from other task-switching procedures: The explicit task-cuing procedure presents enough information on a single trial to determine the correct response. The cue and the

\footnotetext{
${ }^{1}$ The expression presupposes that $\mu_{\mathrm{c}} \neq \mu_{\mathrm{s}}$. By Model 1, the probability that cue encoding is complete but set switching is not complete at time SOA equals

$$
\int_{0}^{\text {SOA }}\left(1 / \mu_{\mathrm{c}}\right) \cdot \exp \left[-t / \mu_{\mathrm{c}}\right] \cdot \exp \left[-(\operatorname{SOA}-t) / \mu_{\mathrm{s}}\right] d t
$$

If $\mu_{\mathrm{c}} \neq \mu_{\mathrm{s}}$, the integral reduces to the stated expression,

$$
\frac{1 / \mu_{\mathrm{c}}}{1 / \mu_{\mathrm{c}}-1 / \mu_{\mathrm{s}}}\left(\exp \left[-\mathrm{SOA} / \mu_{\mathrm{s}}\right]-\exp \left[-\mathrm{SOA} / \mu_{\mathrm{c}}\right]\right) .
$$

If $\mu_{\mathrm{c}}=\mu_{\mathrm{s}}=\mu$, then the integral reduces to

$$
(\mathrm{SOA} / \mu) \exp [-\mathrm{SOA} / \mu] \text {. }
$$

${ }^{2}$ In Models 1 and 2, cue-encoding times and set-switching times are distributed exponentially. However, the predictions by Models 1 and 2 described in Appendix A hold not only when exponential distributions of cue-encoding and set-switching times are assumed. We have examined many alternative versions of Model 1 and Model 2 with distributions belonging to the family of generalized gammas (see, e.g., McGill, 1963) and found the same basic pattern of predicted results.
} 
target act as a compound stimulus that uniquely determines the correct response. For example, in our experiments, the cue OddEven and the target 7 mapped uniquely onto the 4 key on the numeric keypad that we used to collect responses. From this perspective, there is no endogenous act of control that prolongs RT on task-alternation trials. Instead, there may be a benefit from repeating the cue-part of the compound stimulus-on taskrepetition trials.

We explain the benefit from repeating the cue by formalizing the cue-encoding process in terms of Bundesen's (1990) theory of visual attention (TVA; see also Bundesen, 1998a, 1998b; Bundesen \& Harms, 1999; Logan, 1996, 2002; Logan \& Gordon, 2001). We assume that the current cue is compared to memory representations of the alternative cues and that cue encoding occurs when the current cue matches one of the representations. In TVA, encoding time is distributed exponentially, with a rate parameter that increases in proportion to the similarity of the presented cue to a representation of the cue. The more similar the current cue to the representation, the faster the cue is encoded. We assume that there is a short-term memory representation of the cue from the last trial that is also compared with the current cue. Cue encoding occurs when the current cue matches either a long-term memory representation or the short-term memory representation. Following TVA, the two comparison processes race against each other, and the first one to finish determines performance. On repetition trials, the cue matches both the short-term memory representation and a long-term memory representation, so the rate at which the cue is processed equals the sum of the comparison rates for short-term and long-term memory (i.e., $\nu_{\mathrm{STM}}+\nu_{\mathrm{LTM}}$, where $\nu_{\mathrm{STM}}$ and $\nu_{\mathrm{LTM}}$ are the rates at which the cue is compared with short-term memory and long-term memory, respectively). On alternation trials, the current cue will not match the short-term memory representation, so only the long-term memory representation effectively enters the race. Thus, the cue-encoding rate on alternation trials will equal the comparison rate for long-term memory (i.e., $\nu_{\text {LTM }}$ ). TVA assumes that finishing times are distributed exponentially, so the mean finishing time equals the reciprocal of the processing rates. Thus, the mean cue-encoding time on repetition trials, $\mu_{\mathrm{r}}$, is

$$
\mu_{\mathrm{r}}=\frac{1}{\nu_{\mathrm{STM}}+\nu_{\mathrm{LTM}}},
$$

and the mean cue-encoding time on alternation trials, $\mu_{\mathrm{a}}$, is

$$
\mu_{\mathrm{a}}=\frac{1}{\nu_{\mathrm{LTM}}} .
$$

Consequently, $\mu_{\mathrm{r}}<\mu_{\mathrm{a}}$. Model 2 predicts faster RT on repetition trials than on alternation trials.

Interaction between repetition versus alternation and SOA. The benefit from repeating the cue should appear at short SOAs when cue encoding has not had time to finish, and it should disappear at long SOAs when cue encoding is complete. Thus, Model 2 also predicts an interaction between SOA and repetition and alternation. On repetition trials, the probability that cue encoding is finished at a given $\mathrm{SOA}$ is equal to $F(\mathrm{SOA})=1-$ $\exp \left[-\mathrm{SOA} / \mu_{\mathrm{r}}\right]$ and the probability that it is not finished is equal to $1-F(\mathrm{SOA})=\exp \left[-\mathrm{SOA} / \mu_{\mathrm{r}}\right]$. Thus, mean $\mathrm{RT}$ is

$$
\mathrm{RT}_{\text {Repetition }}=\mathrm{RT}_{\text {Base }}+\mu_{\mathrm{r}} \cdot \exp \left[-\mathrm{SOA} / \mu_{\mathrm{r}}\right],
$$

where $\mathrm{RT}_{\mathrm{Base}}$ is the time to process the target and produce a response, as it was in Model 1. By a similar argument, mean RT on task alternation trials is

$$
\mathrm{RT}_{\text {Alternation }}=\mathrm{RT}_{\text {Base }}+\mu_{\mathrm{a}} \cdot \exp \left[-\mathrm{SOA} / \mu_{\mathrm{a}}\right] .
$$

The difference in mean RT between cue alternation and repetition is

$$
\begin{aligned}
\mathrm{RT}_{\text {Alternation }}-\mathrm{RT}_{\text {Repetition }}=\mu_{\mathrm{a}} \cdot \exp [ & \left.-\mathrm{SOA} / \mu_{\mathrm{a}}\right] \\
& -\mu_{\mathrm{r}} \cdot \exp \left[-\mathrm{SOA} / \mu_{\mathrm{r}}\right] .
\end{aligned}
$$

If SOA $=0$, this difference equals $\mu_{\mathrm{a}}-\mu_{\mathrm{r}}$, which can take on any positive value. As SOA increases, this difference gets smaller and approaches 0 , producing the predicted interaction between repetition versus alternation and SOA.

Interaction between repetition versus alternation and prolongation of cue-encoding time. The TVA analysis of repetition generally predicts an underadditive interaction between repetition versus alternation and our masking manipulation in Experiments 1 and 2. Masking the cue will reduce the similarity between the current cue and its long-term memory representation on both repetition and alternation trials. Thus, $\nu_{\mathrm{LTM}} \mid$ no mask $>$ $\nu_{\text {LTM }} \mid$ mask. Masking the cue will also reduce the similarity between the current cue and the short-term memory representation. This reduction in similarity will have a strong effect on repetition trials, where the cue represented in short-term memory matches the current cue, but it will have little effect on alternation trials, where the cue represented in short-term memory does not match the current cue. Indeed, masking will reduce the similarity between the cue and the short-term memory representation more than it reduces the similarity between the cue and the long-term memory representation. On masking trials, short-term memory contains a representation of a degraded cue that is compared with the current degraded cue. Cue characters are masked randomly, so different characters are likely to be masked from one trial to the next. There are 10 characters in each cue display, and 5 are masked randomly, so, on average, only 2.5 characters in the short-term memory representation should match the current cue. By contrast, 5 characters in the long-term memory representation should match the current cue because the long-term memory representation is not degraded. Thus, $\nu_{\mathrm{STM}} \mid$ no mask $>\nu_{\mathrm{STM}} \mid$ mask. The match to short-term memory contributes little to the race on masking trials, so cue-encoding time is prolonged substantially.

This analysis leads to the following ordinal predictions:

$$
\begin{aligned}
& \mu_{\mathrm{a}} \mid \text { mask }>\mu_{\mathrm{a}} \mid \text { no mask, } \\
& \mu_{\mathrm{r}} \mid \text { mask }>\mu_{\mathrm{r}} \mid \text { no mask, } \\
& \mu_{\mathrm{a}} \mid \text { no mask }>\mu_{\mathrm{r}} \mid \text { no mask, }
\end{aligned}
$$

and

$$
\mu_{\mathrm{a}} \mid \text { mask }>\mu_{\mathrm{r}} \mid \text { mask }
$$

Model 2 predicts an underadditive interaction between repetition and masking in the estimated cue-encoding times, that is

$$
\left(\mu_{\mathrm{a}}-\mu_{\mathrm{r}}\right) \mid \text { no mask }>\left(\mu_{\mathrm{a}}-\mu_{\mathrm{r}}\right) \mid \text { mask },
$$

if and only if 
$\nu_{\mathrm{STM} \mid \mathrm{mask}}$

$$
<\frac{\nu_{\mathrm{STM} \mid \text { no mask }} \cdot\left(\nu_{\mathrm{LTM} \mid \text { mask }}\right)^{2}}{\left(\nu_{\mathrm{LTM} \mid \text { no mask }}\right)^{2}+\nu_{\mathrm{STM} \mid \text { no mask }} \cdot\left(\nu_{\mathrm{LTM} \mid \text { no mask }}-\nu_{\mathrm{LTM} \mid \text { mask }}\right)} .
$$

The right-hand side of the inequality will always be positive because all the terms are positive and $\nu_{\mathrm{LTM} \mid \text { no mask }}>\nu_{\mathrm{LTM} \mid \text { mask }}$. Thus, for any values of $\nu_{\mathrm{STM} \mid \text { no mask }}, \nu_{\mathrm{LTM} \mid \text { no mask }}$, and $\nu_{\mathrm{LTM} \mid \text { mask }}$, Model 2 predicts an underadditive interaction between repetition and masking if $\nu_{\mathrm{STM} \mid \text { mask }}$ is sufficiently small. Model 2 will predict a null interaction if the two sides of the inequality are equal, and it will predict an overadditive interaction if the left-hand side is greater than the right-hand side. Thus, Model 2 is consistent with an underadditive interaction between repetition and masking, whereas Model 1 is not. An underadditive interaction between repetition and masking would falsify Model 1 and be consistent with Model 2.

We tested these predictions by fitting Model 2 to the data and examining the values of the best-fitting parameters. As with Model 1 , we tested the predicted interaction in two related ways. First, we calculated the interaction contrast involving repetition and masking effects at $\mathrm{SOA}=0$. According to Equation 6, the difference between repetition and alternation $\mathrm{RT}$ at $\mathrm{SOA}=0$ is simply $\mu_{\mathrm{a}}-$ $\mu_{\mathrm{r}}$. Thus, the underadditive interaction that is consistent with Model 2 can be tested by computing the interaction contrast at $\mathrm{SOA}=0$. Second, we tested the interaction contrast by averaging RT over SOA. Again, intuition might suggest that the interaction contrast would remain underadditive but diminish in magnitude as SOA increases. However, a formal analysis of Model 2, presented in Appendix A, shows that the interaction diminishes as SOA increases but switches from underadditive to overadditive when SOA is sufficiently long (see Footnote 2).

\section{Model 2+1: Benefit for Repetition and an Endogenous Act of Control}

We constructed a third model that combines the cue-encoding assumptions of Model 2 with the set-switching assumptions of Model 1. According to this new model, Model 2+1, mean RT on repetition trials is

$$
\mathrm{RT}_{\text {Repetition }}=\mathrm{RT}_{\text {Base }}+\mu_{\mathrm{r}} \cdot \exp \left[-\mathrm{SOA} / \mu_{\mathrm{r}}\right],
$$

and mean RT on alternation trials is

$$
\begin{array}{r}
\mathrm{RT}_{\text {Alternation }}=\mathrm{RT}_{\text {Base }}+\exp \left[-\mathrm{SOA} / \mu_{\mathrm{a}}\right] \cdot\left(\mu_{\mathrm{a}}+\mu_{\mathrm{s}}\right) \\
+\frac{1 / \mu_{\mathrm{a}}}{1 / \mu_{\mathrm{a}}-1 / \mu_{\mathrm{s}}}\left(\exp \left[-\mathrm{SOA} / \mu_{\mathrm{s}}\right]\right. \\
\left.\quad-\exp \left[-\mathrm{SOA} / \mu_{\mathrm{a}}\right]\right) \cdot \mu_{\mathrm{s}},
\end{array}
$$

where $\mu_{\mathrm{r}}$ is the mean cue-encoding time on repetition trials, $\mu_{\mathrm{a}}$ is the mean cue-encoding time on alternation trials, and $\mu_{\mathrm{s}}$ is the mean set-switching time. Note that Equation 7 is the same as Equation 4, and Equation 8 is the same as Equation 2, with $\mu_{\mathrm{a}}$ substituted for $\mu_{\mathrm{c}}$.

Models 1 and 2 are "nested" in Model $2+1$. Consider the relation between Model $2+1$ and Model 2. Model 2+1 involves the same parameters as Model 2 plus one additional parameter, $\mu_{\mathrm{s}}$. If $\mu_{\mathrm{s}}$ vanishes, then Equations 7 and 8 reduce to Equations 4 and 5 . We tested Model $2+1$ by fitting it to the data and comparing its goodness of fit with that of Model 2. If the extra parameter captures an important process, then Model $2+1$ should fit significantly better than Model 2 . We also examined the values of the best-fitting parameters for Model $2+1$. The values of $\mu_{\mathrm{r}}$ and $\mu_{\mathrm{a}}$ should obey the same inequalities predicted for Model 2. If they violate the predicted inequalities, the fit by Model $2+1$ can be rejected.

\section{Experiment 1}

The first experiment tested 3 subjects over several sessions to obtain stable data for model fitting. The experiment involved three number-classification tasks: magnitude, in which subjects decided whether numbers were greater or less than 5; parity, in which subjects decided whether numbers were odd or even; and form, in which subjects decided whether numbers were presented as digits or words. A cue indicating which task to perform was presented at one of 20 SOAs before each target. We used a large number of SOAs in order to capture the shape of the time-course function and constrain the model fits. Cues, targets, and SOAs appeared in random order, and the data were separated into repetition and alternation trials post hoc. For half of the sessions, the cue was masked to prolong cue-encoding time. Model 1 predicts no interaction between repetition and masking at $\mathrm{SOA}=0$ and overadditive interaction at all SOAs $>0$. Model 2 predicts underadditive interaction at short SOAs and overadditive interaction at sufficiently long SOAs, but the model is consistent with underadditive interactions at all SOAs we tested. Model $2+1$ predicts an underadditive interaction at short SOAs and a significant increase in goodness of fit over Model 2.

\section{Method}

Subjects. The subjects were three students from Vanderbilt University who were paid for their participation in 2 practice sessions and 16 experimental sessions. One was female and 2 were male.

Apparatus and stimuli. The stimuli were presented on Gateway 2000 Crystalscan 1024 NI monitors controlled by Gateway 2000486 computers. The cues were High-Low, Odd-Even, and Digit-Word, and the targets were the digits $1,2,3,4,6,7,8$, and 9 and the words one, two, three, four, six, seven, eight, and nine. The cues appeared centered on the screen and the targets appeared one line $(2.5 \mathrm{~mm})$ below them, also centered on the screen. Cues and targets were white on a black background. The cue display was preceded by a fixation display, which consisted of two plus signs $(+)$. One was presented one line above the line on which the cue would appear, and one was presented one line below the line on which the target would appear. The plus signs were also white on a black background

The cues and targets were $5 \mathrm{~mm}$ high. High-Low and Odd-Even were 25 $\mathrm{mm}$ wide, and Digit-Word was $30 \mathrm{~mm}$ wide. Digit targets were $3 \mathrm{~mm}$ wide. Word targets were 10 (one, two, six), 12.5 (four, nine), and 15 (three, seven, eight) $\mathrm{mm}$ wide. The fixation display was exposed for $500 \mathrm{~ms}$. Viewing distance was not constrained but was approximately $60 \mathrm{~cm}$. At this distance, $1 \mathrm{~cm}$ is approximately $1^{\circ}$ of visual angle.

The cue display was exposed for SOA ms, where SOA was 0, 50, 100, 150, 200, 250, 300, 350, 400, 450, 500, 550, 600, 650, 700, 750, 800, 850, 900 , or $950 \mathrm{~ms}$. The cue remained on the screen when the target was presented, and the cue and target were exposed until the subject responded. After the subject's response, the screen went blank for a 500-ms intertrial interval (ITI).

Responses were collected from the numeric keypad. Each subject pressed 7 to indicate "High," 9 to indicate "Low," 4 to indicate "Odd," 6 to indicate "Even," 1 to indicate "Digit," and 3 to indicate "Word." This mapping allowed us to distinguish between same-task errors (e.g., indicating "High" when "Low" was appropriate) and different-task errors (e.g., 
indicating "Odd" when "Low" was appropriate). Note that the cues were consistent with the response mapping (e.g., the cue High-Low specified the left-right order of the responses on the keypad). Subjects used the index and middle fingers of their right hands to press the keys. The use of different keys for different tasks required subjects to move their hands from one row to another on alternation trials but not on repetition trials. We ran another 3 subjects through 18 sessions (2 practice sessions and 16 test sessions) with the requirement to respond to all three tasks with the same keys (4 and 6 on the numeric keypad) and found essentially the same results. Their data are discussed further in the Limitations section of the General Discussion.

On masking trials, five pound signs (\#) were superimposed on the cue in random positions. The cues were presented in fields of 10 character positions, and half of these positions were filled with masks on each trial. With this arrangement, there was always enough information to specify each cue uniquely. The assignment of masks to positions was randomized on each trial, so cue repetitions looked different from one trial to the next (e.g., \#ig\#t\#W\#\#d $\Rightarrow$ D\#\#it\#W\#r\#).

Procedure. The basic design involved 3 (cues) $\times 16$ (targets) $\times 20$ $($ SOAs $)=960$ trials. Each session involved one replication of the basic design. Masking was manipulated between sessions. Subjects 2 and 3 began with a single-task practice session in which they performed 110 trials with each of the three tasks (magnitude, parity, and form). The purpose was to familiarize them with each task and the mapping of response categories onto the numeric keypad. Next, they performed a 960-trial practice session with the program from Experiment 2 (see below). The three tasks were mixed randomly, with cues presented at 10 different SOAs $(0,100,200,300,400,500,600,700,800$, and $900 \mathrm{~ms})$ covering the range they would experience during the experimental trials. They did 480 trials with no mask and then 480 trials with a mask. The purpose was to familiarize them with the conditions they would experience in the experimental sessions. Subject 1 did the practice sessions in the opposite order.

Then each subject performed 16 experimental sessions of 960 trials, 8 sessions with no mask and 8 sessions with a mask. Subjects began with no mask on the first session and alternated between mask and no mask on subsequent sessions. All three tasks were included, as were all 20 SOAs. Subjects were allowed brief breaks every 96 trials. At the end of each experimental session, subjects were told their mean RT and their percentage of correct responses for that session. They were encouraged to do as well or better on the next session. The data were analyzed as a function of masking, SOA, and repetition versus alternation. There were approximately 128 repetition trials and 256 alternation trials for each subject at each SOA in each masking condition.

\section{Results and Discussion}

Accuracy was high ( $M=98 \%, 96 \%$, and $97 \%$ for Subjects 1, 2, and 3, respectively) and did not trade off with RT, so the analyses focused on RT. (The accuracy data and mean RTs for all of the present experiments can be found in Appendixes B-F in the online version of this article, which is part of the PsycARTICLES database.) The data were sorted into repetition and alternation trials post hoc. The mean RTs in each cell of the 2 (repetition vs. alternation) $\times 2$ (mask vs. no mask) $\times 20$ (SOA) design appear in Figures 1, 2, and 3. Figure 1 contains the data and model fits for Subject 1, Figure 2 contains the data and model fits for Subject 2, and Figure 3 contains the data and model fits for Subject 3 .

Standard analyses. Each subject showed faster RTs and higher accuracy on repetition trials than on alternation trials and faster RTs and higher accuracy with no mask than with a mask. Each subject showed a negatively accelerated reduction in RT as SOA increased and a reduction in the effects of repetition and masking as SOA increased. Thus, the main experimental manipulations were successful.
Each subject showed an underadditive interaction between repetition versus alternation and mask versus no mask (i.e., $\mathrm{RT}_{\text {Mask-Alternation }}-\mathrm{RT}_{\text {Mask-Repetition }}-\mathrm{RT}_{\text {No-Mask-Alternation }}+$ $\left.\mathrm{RT}_{\text {No-Mask-Repetition }}<0\right)$. The interaction contrasts were negative at SOA $=0$ (the values were $-60,-32$, and -22 for Subjects 1 , 2 , and 3 , respectively) and negative when averaged over SOA (the values were $-21,-7$, and -21 for Subjects 1,2 , and 3, respectively). Subject 1 showed negative interaction contrasts at 14 of the 20 SOAs ( 9 in the first 10 SOAs and 5 in the last 10). Subject 2 showed negative interaction contrasts at 10 of the 20 SOAs ( 7 in the first 10 SOAs and 3 in the last 10). Subject 3 showed negative interaction contrasts in 17 of the 20 SOAs (10 in the first 10 SOAs and 7 in the last 10). These results are inconsistent with Model 1, which predicts a null interaction at $\mathrm{SOA}=0$ and positive interaction contrasts at all SOAs $>0$. They are consistent with Model 2 , which generally predicts negative interaction contrasts at short SOAs reducing in magnitude and becoming positive as SOA becomes sufficiently long.

Model fitting. We fit the models to the data from each subject using the Solver procedure in Microsoft Excel, minimizing the sum of squared deviations between observed and predicted values. The values of the best-fitting parameters for each model and measures of goodness of fit-root-mean-squared deviation between observed and predicted values (RMSD) and the productmoment correlation between observed and predicted values $(r)$ appear in Table 1.

First, we fit a constrained version of Model 1 (Model 1 Constrained). We used Equation 1 for the no-mask and mask repetition conditions and Equation 2 for the no-mask and mask alternation conditions. There were 80 data points and four free parameters per subject: a common value of $\mathrm{RT}_{\text {Base }}$ for all conditions, a different value of $\mu_{\mathrm{c}}$ for no-mask and for mask conditions, and a single value of $\mu_{\mathrm{s}}$, in alternation conditions for both no-mask and mask trials. Model 1 Constrained was constrained in the sense that we required the value of $\mu_{\mathrm{s}}$ to be the same with and without a mask. Model 1 Constrained produced good fits overall. The average RMSD was $25 \mathrm{~ms}$, and the average $r$ was .980 .

Next, we fit an unconstrained version of Model 1 (Model 1 Unconstrained), using Equation 1 for repetition conditions and Equation 2 for alternation conditions. There were five free parameters: a common value of $\mathrm{RT}_{\text {Base }}$, a different value of $\mu_{\mathrm{c}}$ for no-mask and for mask conditions, and a different value of $\mu_{\mathrm{s}}$ for no-mask and for mask conditions. Model 1 Unconstrained was unconstrained in that we allowed $\mu_{\mathrm{s}}$ to take on different values with and without a mask. Overall, Model 1 Unconstrained produced better fits than Model 1 Constrained. The average RMSD decreased to $24 \mathrm{~ms}$ and the average $r$ increased to .981 . The increase in goodness of fit was significant in Subjects 1 and 3, $F(1$, $74)=9.88$ and 4.37 , respectively, $p$ s $<.05$. However, the improvement in goodness of fit was bought at the cost of violating Model 1's assumption that set-switching time is unaffected by factors that prolong cue-encoding time: $\mu_{\mathrm{s}}$ was smaller when the cue was masked than when it was not masked for all three subjects.

We fit Model 2 by applying Equation 4 to the repetition conditions and Equation 5 to the alternation conditions. There were five free parameters: a common value of $\mathrm{RT}_{\text {Base }}$ for all conditions, separate values of $\mu_{\mathrm{r}}$ for no-mask and for mask conditions, and separate values of $\mu_{\mathrm{a}}$ for no-mask and for mask conditions. Overall, the fits were about as good as the fits of Model 1. The average (text continues on page 584) 


\section{Subject 1}

No Mask
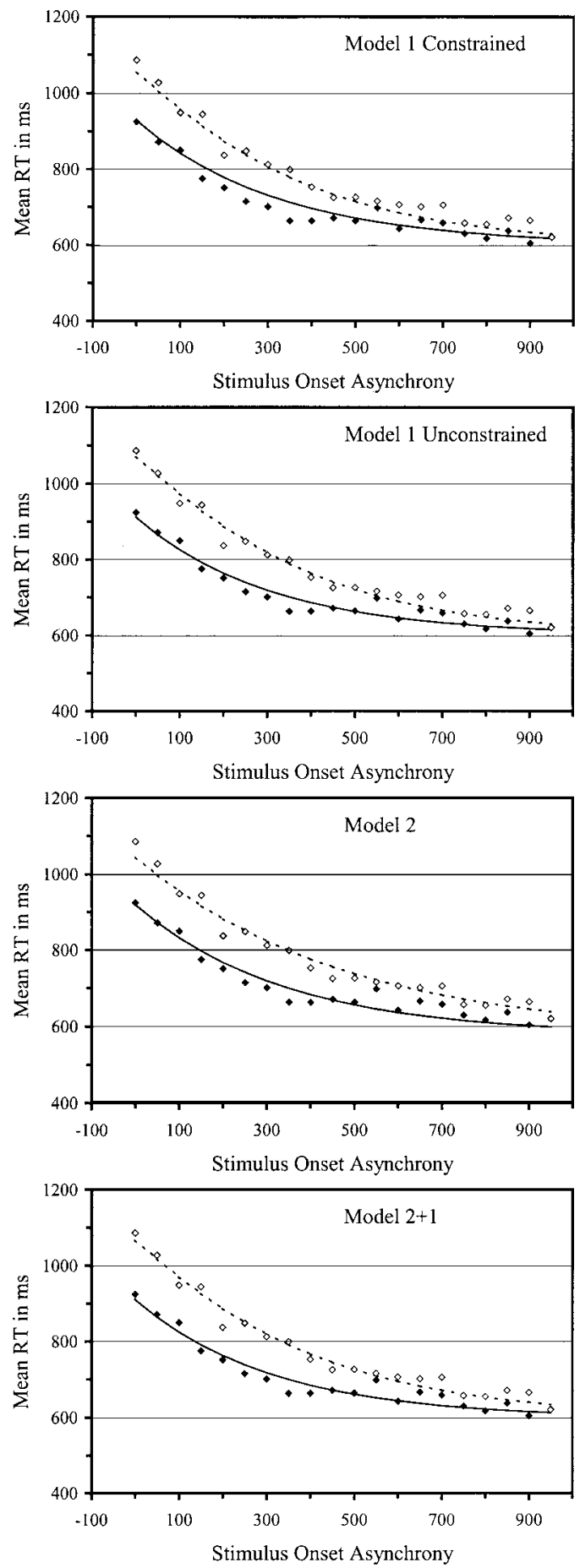

Mask
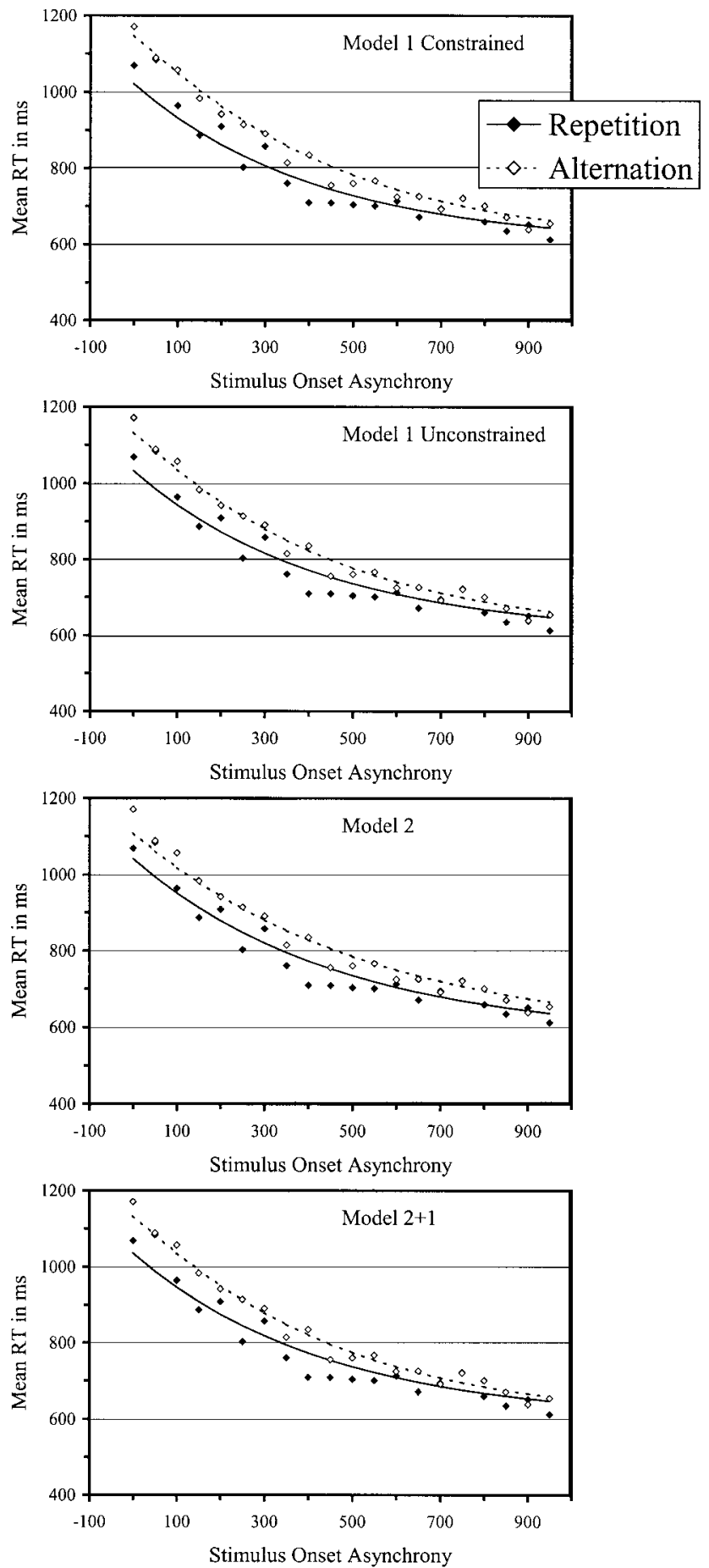

Figure 1. Mean reaction times (RTs) for Subject 1 in Experiment 1 as functions of stimulus onset asynchrony in no-mask (left panels) and mask (right panels) conditions. The points represent the observed data. Solid diamonds represent task-repetition trials. Open diamonds represent task-alternation trials. The lines represent predictions from the models. Solid lines represent predictions for task-repetition trials. Broken lines represent predictions for task-alternation trials. 


\section{Subject 2}
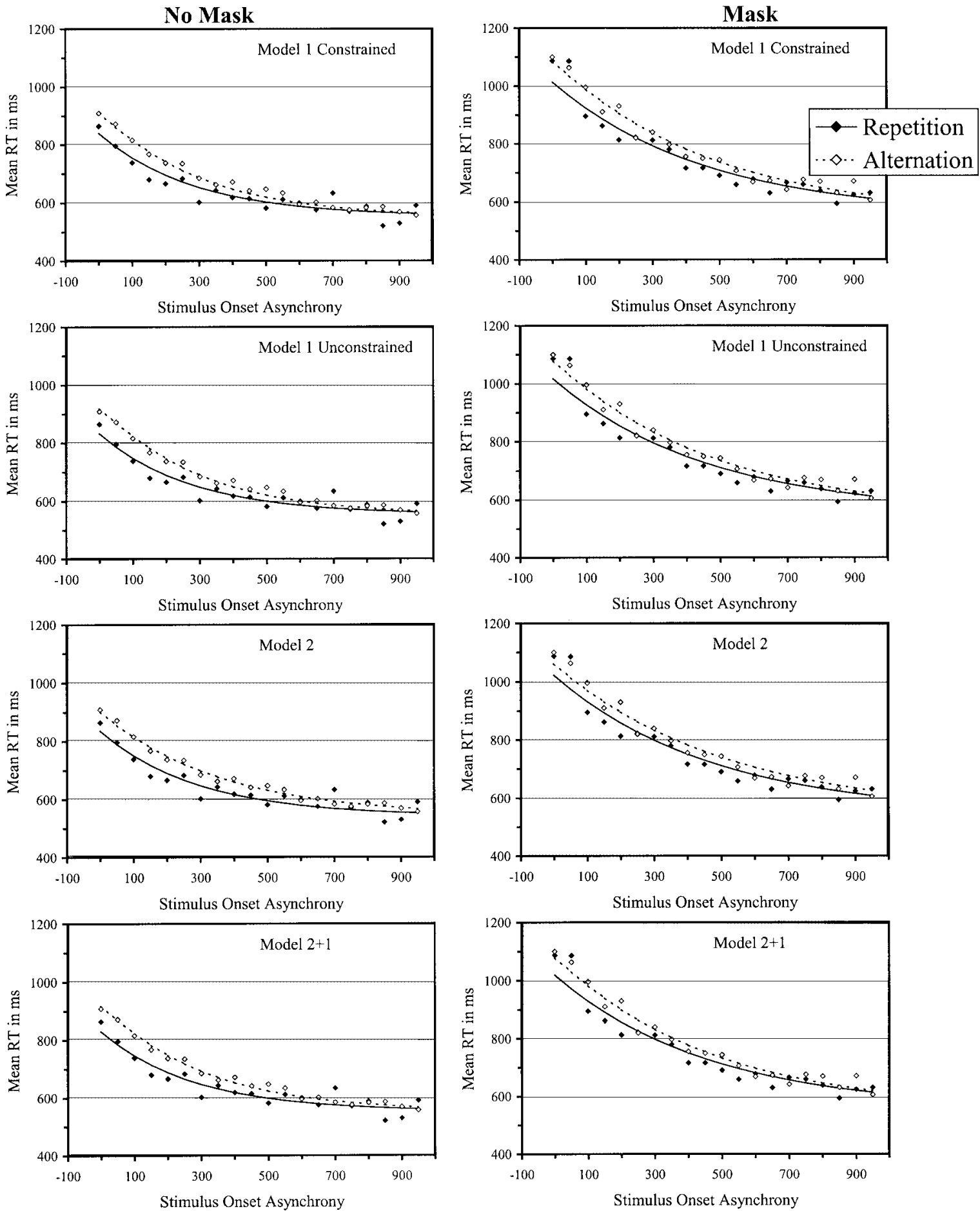

Figure 2. Mean reaction times (RTs) for Subject 2 in Experiment 1 as functions of stimulus onset asynchrony in no-mask (left panels) and mask (right panels) conditions. The points represent the observed data. Solid diamonds represent task-repetition trials. Open diamonds represent task-alternation trials. The lines represent predictions from the models. Solid lines represent predictions for task-repetition trials. Broken lines represent predictions for task-alternation trials. 
Subject 3
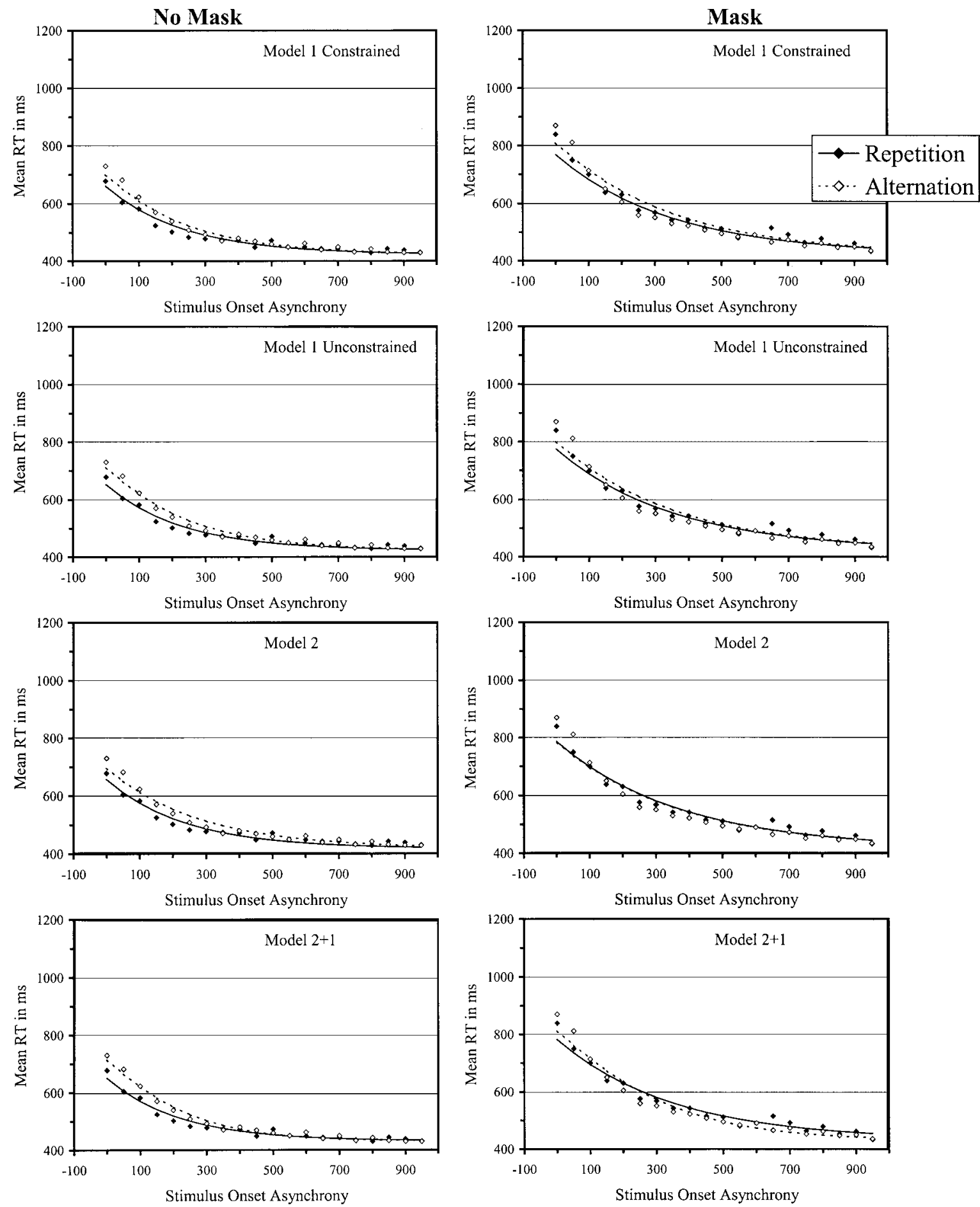

Figure 3. Mean reaction times (RTs) for Subject 3 in Experiment 1 as functions of stimulus onset asynchrony in no-mask (left panels) and mask (right panels) conditions. The points represent the observed data. Solid diamonds represent task-repetition trials. Open diamonds represent task-alternation trials. The lines represent predictions from the models. Solid lines represent predictions for task-repetition trials. Broken lines represent predictions for task-alternation trials. 
Table 1

Values (in ms) of Best-Fitting Parameters and Measures of Goodness of Fit for the Models for Fits to 3 Subjects in Experiment 1

\begin{tabular}{|c|c|c|c|c|c|c|c|c|}
\hline Subject & $\mathrm{RT}_{\text {Base }}$ & $\mu_{\mathrm{c}} \mid \mathrm{nm}$ & $\mu_{\mathrm{c}} \mid \mathrm{m}$ & $\mu_{\mathrm{s}}$ & & & $r$ & RMSD \\
\hline \multicolumn{9}{|c|}{ Model 1 Constrained } \\
\hline 1 & 599 & 328 & 422 & 127 & & & .979 & 28 \\
\hline 2 & 551 & 287 & 462 & 72 & & & .980 & 27 \\
\hline \multirow[t]{2}{*}{3} & 422 & 238 & 347 & 40 & & & .981 & 20 \\
\hline & $\mathrm{RT}_{\text {Base }}$ & $\mu_{\mathrm{c}} \mid \mathrm{nm}$ & $\mu_{\mathrm{c}} \mid \mathrm{m}$ & $\mu_{\mathrm{s}} \mid \mathrm{nm}$ & $\mu_{\mathrm{s}} \mid \mathrm{m}$ & & $r$ & RMSD \\
\hline \multicolumn{9}{|c|}{ Model 1 Unconstrained } \\
\hline 1 & 600 & 311 & 432 & 160 & 101 & & .982 & 26 \\
\hline 2 & 552 & 281 & 464 & 87 & 62 & & .980 & 27 \\
\hline \multirow[t]{2}{*}{3} & 423 & 229 & 352 & 60 & 26 & & .982 & 20 \\
\hline & $\mathrm{RT}_{\text {Base }}$ & $\mu_{\mathrm{r}} \mid \mathrm{nm}$ & $\mu_{\mathrm{a}} \mid \mathrm{nm}$ & $\mu_{\mathrm{r}} \mid \mathrm{m}$ & $\mu_{\mathrm{a}} \mid \mathrm{m}$ & & $r$ & RMSD \\
\hline \multicolumn{9}{|c|}{ Model 2} \\
\hline 1 & 577 & 342 & 468 & 464 & 532 & & .980 & 28 \\
\hline 2 & 540 & 296 & 362 & 482 & 522 & & .980 & 27 \\
\hline \multirow[t]{2}{*}{3} & 417 & 239 & 279 & 369 & 367 & & .980 & 21 \\
\hline & $\mathrm{RT}_{\text {Base }}$ & $\mu_{\mathrm{r}} \mid \mathrm{nm}$ & $\mu_{\mathrm{a}} \mid \mathrm{nm}$ & $\mu_{\mathrm{r}} \mid \mathrm{m}$ & $\mu_{\mathrm{a}} \mid \mathrm{m}$ & $\mu_{\mathrm{s}}$ & $r$ & RMSD \\
\hline \multicolumn{9}{|c|}{ Model $2+1$} \\
\hline 1 & 597 & 313 & 358 & 438 & 425 & 112 & .982 & 26 \\
\hline 2 & 551 & 279 & 296 & 468 & 458 & 71 & .980 & 27 \\
\hline 3 & 430 & 220 & 112 & 352 & 173 & 173 & .987 & 17 \\
\hline
\end{tabular}

Note. $\quad \mathrm{RT}=$ reaction time; $\mu_{\mathrm{c}}=$ mean cue-processing time; $\mu_{\mathrm{s}}=$ mean set-switching time; $\mu_{\mathrm{r}}=$ mean cue-processing time on repetition trials; $\mu_{\mathrm{a}}=$ mean cue-processing time on alternation trials; $\mathrm{nm}=$ no mask on cue; $\mathrm{m}=$ mask on cue; $r=$ correlation between predicted and observed values; RMSD = root-mean-squared deviation between predicted and observed values.

RMSD was $25 \mathrm{~ms}$ and the average $r$ was .980 . Moreover, the values of the best-fitting parameters confirmed Model 2's ordinal predictions: $\mu_{\mathrm{r}} \mid$ no mask was less than $\mu_{\mathrm{r}} \mid$ mask, $\mu_{\mathrm{a}} \mid$ no mask was less than $\mu_{\mathrm{a}} \mid$ mask, and $\mu_{\mathrm{r}} \mid$ no mask was less than $\mu_{\mathrm{a}} \mid$ no mask for all 3 subjects. The value of $\mu_{\mathrm{r}} \mid$ mask was smaller than the value of $\mu_{\mathrm{a}} \mid$ mask in Subjects 1 and 2 and larger by only $2 \mathrm{~ms}$ in Subject 3. Each subject showed the negative interaction contrast predicted by Model 2, that is $\left(\mu_{\mathrm{a}}-\mu_{\mathrm{r}}\right) \mid$ no mask $>\left(\mu_{\mathrm{a}}-\mu_{\mathrm{r}}\right) \mid$ mask.

We fit Model $2+1$ by applying Equation 7 to repetition conditions and Equation 8 to alternation conditions. There were six free parameters: a common value of $\mathrm{RT}_{\text {Base }}$ for all conditions, separate values of $\mu_{\mathrm{r}}$ for no-mask and for mask conditions, separate values of $\mu_{\mathrm{a}}$ for no-mask and for mask conditions, and a single value of $\mu_{\mathrm{s}}$ for both alternation conditions. Model $2+1$ had more parameters than the other models, and it fit the data best overall. The average RMSD was $23 \mathrm{~ms}$ and the average $r$ was .983. The improvement in goodness of fit over Model 2 was significant in Subjects 1 and $3, F(1,73)=10.58$ and 38.27, respectively, $p \mathrm{~s}<.01$. However, the improvement in goodness of fit was bought at the cost of violating Model 2's assumptions: $\mu_{\mathrm{r}} \mid$ mask was larger than $\mu_{\mathrm{a}} \mid$ mask in all three subjects, and $\mu_{\mathrm{r}} \mid$ no mask was larger than $\mu_{\mathrm{a}} \mid$ no mask in Subject 3.

\section{Conclusions}

All 3 subjects showed underadditive interactions between repetition and masking that contradicted the predictions of Model 1 and were consistent with Model 2. The underadditive interactions appeared in the RT data and in the estimates of cue-encoding time derived from the fits of Model 2. The unconstrained version of Model 1 was only able to account for these interactions by allowing set-switching time, $\mu_{\mathrm{s}}$, to speed up when the cue was masked, which violates Model 1's assumption that set-switching time is unaffected by factors that prolong cue encoding. Model $2+1$, which incorporated Model 2's assumptions about cue-repetition effects and Model 1's assumption about set switching on alternation trials, fit the data best, but it did so only by violating Model 2's assumption that cue-processing time is faster on repetition trials than on alternation trials. Thus, Model 2 appears to provide the best account of the data. This challenges the idea that the explicit task-cuing procedure involves an endogenous act of control-set switching - that accounts for the difference in RT between alternation and repetition trials.

\section{Experiment 2}

The results of Experiment 1 were obtained with highly practiced subjects. It is possible that the extensive practice they experienced allowed them to learn to treat cues and targets as compound stimuli and that this allowed them to do the tasks without switching sets - that is, to behave in accord with Model 2 rather than Model 1 or Model $2+1$. The second experiment was designed to compare the alternative models in relatively unpracticed subjects, who 
served only in a single session. If extensive practice is necessary for subjects to treat cues and targets as compound stimuli, Model 2 should not provide a better account of data from relatively unpracticed subjects.

Experiment 2 was a replication of the conditions of Experiment 1 in a single session. The tasks, cues, and targets were the same, and the cues were masked for half of the trials and not masked for the other half. There were only 10 SOAs-0, 100, 200, 300, 400, $500,600,700,800$, and $900 \mathrm{~ms}$ - but they spanned the same range as the SOAs in Experiment 1. We tested 32 subjects instead of 3. The larger number of subjects allowed us to test the interaction between repetition versus alternation and no-mask versus mask with a conventional analysis of variance (ANOVA). It also allowed us much greater statistical power in comparing the values of parameters of models fitted to the data. As in Experiment 1, we fitted Model 1 Constrained, Model 1 Unconstrained, Model 2, and Model $2+1$ to the data and examined the values of the best-fitting parameters to see if they confirmed or disconfirmed the assumptions of the models.

\section{Method}

Subjects. The subjects were 32 students from an introductory psychology class who participated to fulfill course requirements. None had served in Experiment 1.

Apparatus and stimuli. The apparatus and stimuli were the same as in Experiment 1, except that we used 10 SOAs instead of 20. The SOAs were 0, 100, 200, 300, 400, 500, 600, 700, 800, and $900 \mathrm{~ms}$. As in Experiment 1 , subjects used different rows of the numeric keypad to respond to the different tasks. We replicated Experiment 2 with another group of 32 subjects who responded to all three tasks with the same keys (4 and 6 on the numeric keypad), and we found essentially the same results. Their data are discussed further in the Limitations section of the General Discussion.

Procedure. The procedure was the same as in the experimental sessions of Experiment 1, except that subjects served in a single session, masking was manipulated within the session, and there were 10 SOAs instead of 20 . The basic design involved 3 (cues) $\times 16$ (targets) $\times 10$ $(\mathrm{SOAs})=480$ trials with a mask and 480 trials without a mask. Masking was blocked. Cues, targets, and SOAs appeared in random order within each set of 480 trials. The order was randomized separately for each subject. Half of the subjects performed 480 trials without a mask and then 480 trials with a mask, and half performed trials with a mask before trials without a mask

Subjects were allowed brief rests every 96 trials. They were warned when the masking condition changed in the middle of the experiment.

\section{Results and Discussion}

Standard analyses. Accuracy was high, averaging 92\%, and there was no evidence of a speed-accuracy tradeoff, so the analyses focused on RT. RTs were sorted into repetition and alternation trials post hoc. The mean RTs in each cell of the 2 (repetition vs. alternation) $\times 2$ (mask vs. no mask) $\times 10($ SOA $)$ design are presented in Figure 4.

The RT data replicated standard effects. RT decreased as SOA increased. It was faster for cue-repetition than for cue-alternation trials, and the difference between repetition and alternation decreased as SOA increased. RT was longer when the cue was masked than when it was not masked, particularly at short SOAs.

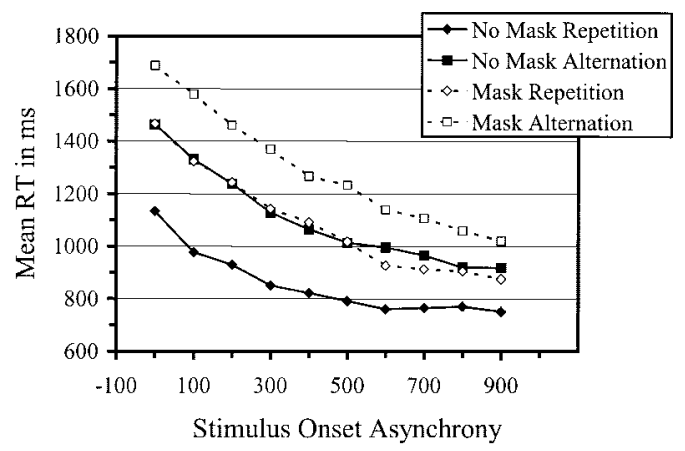

Figure 4. Mean reaction times (RTs) as functions of stimulus onset asynchrony in no-mask and mask conditions of Experiment 2.

The interaction between repetition and masking was underadditive. At $\mathrm{SOA}=0$, the difference between repetition and alternation was $331 \mathrm{~ms}$ without a mask and $222 \mathrm{~ms}$ with a mask. Averaged across SOA, the difference between repetition and alternation was $249 \mathrm{~ms}$ without a mask and $202 \mathrm{~ms}$ with a mask.

These conclusions were supported by a 2 (repetition vs. alternation) $\times 2$ (mask vs. no mask) $\times 10$ (SOA) ANOVA performed on the mean RTs. There were significant main effects of repetition, $F(1,31)=152.92, p<.01, M S E=106,320.55$, masking, $F(1,31)$ $=62.60, p<.01, M S E=14,364,277.51$, and SOA, $F(9,279)=$ $397.97, p<.01, M S E=4,293,459.50$, and significant interactions between repetition and SOA, $F(9,279)=6.93, p<.01, M S E=$ $11,415.97$, and masking and SOA, $F(9,279)=12.93, p<.01$, $M S E=11,354.36$. The theoretically important interaction between repetition and masking was significant as well, $F(1,31)=6.19$, $p<.05, M S E=175,078.83$. A contrast evaluating the interaction between repetition and masking at $\mathrm{SOA}=0$ was significant, $F(1$, 279) $=9.63, p<.01, M S E=9,874.66$.

The accuracy data were submitted to a 2 (repetition vs. alternation) $\times 2$ (mask vs. no mask) $\times 10($ SOA $)$ ANOVA. The main effect of repetition was significant, $F(1,31)=37.30, p<.01$, $M S E=72.54$, reflecting higher accuracy on repetition trials than on alternation trials. The main effect of masking was significant, $F(1,31)=24.34, p<.01, M S E=161.79$, reflecting lower accuracy with a mask than without one. The main effect of SOA was significant, $F(9,279)=7.71, p<.01, M S E=33.37$, reflecting higher accuracy at longer SOAs. None of the interactions were significant.

Model fitting. We fit the models to the 40 mean RTs averaged over subjects and to the 40 mean RTs for each of the 32 subjects individually. We used Equations 1 and 2 for Model 1, forcing $\mu_{\mathrm{s}}$ to be the same in the no-mask and mask conditions in the constrained fits and allowing it to take different values in the no-mask and mask conditions in the unconstrained fits. We used Equations 4 and 5 for Model 2 and Equations 7 and 8 for Model $2+1$.

The models fit the mean data very well. The predicted RTs for each model are plotted against the observed values in Figure 5. The values of the best-fitting parameters and measures of goodness of fit appear in Table 2. Averaged over models, the mean RMSD was $30 \mathrm{~ms}$ and the mean $r$ was .992. As in Experiment 1, Model 1 Unconstrained fit the data better than Model 1 Constrained, $F(1$, $35)=15.92, p<.01$, but at the cost of violating Model 1's assumption that set-switching time is unaffected by factors that 


$$
\begin{array}{|l|}
\rightarrow-\text { No Mask Repetition } \\
-- \text { No Mask Alternation } \\
-\diamond-\text { Mask Repetition } \\
-\square-\text { Mask Alternation } \\
\hline
\end{array}
$$
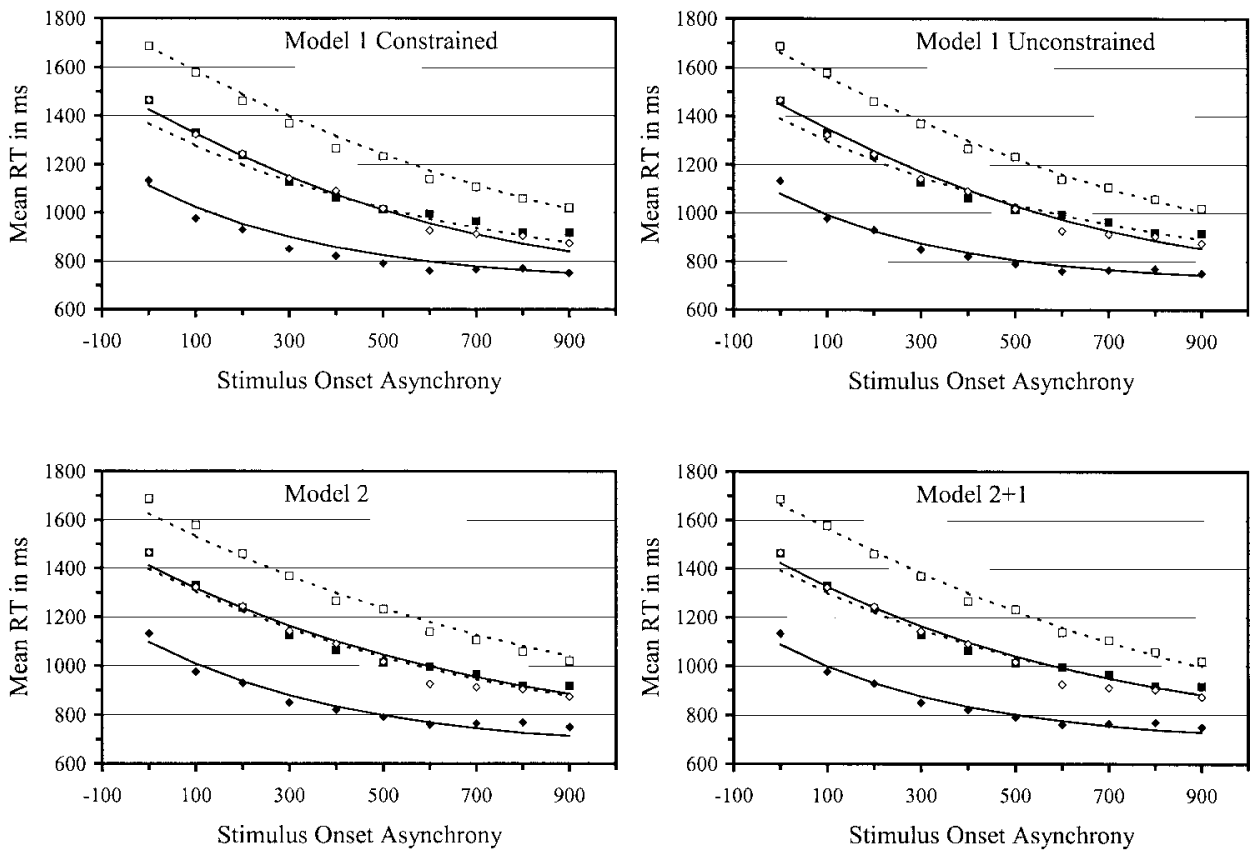

Figure 5. Mean reaction times (RTs) as functions of stimulus onset asynchrony in no-mask and mask conditions in Experiment 2. The points represent the observed data. The lines represent the fits of the model.

prolong cue-encoding time: $\mu_{\mathrm{s}}$ was smaller when the cue was masked than when it was not masked. Model 2 fit the average data well, and its ordinal predictions were confirmed: $\mu_{\mathrm{r}}$ was less than $\mu_{\mathrm{a}}$ with and without a mask, both $\mu_{\mathrm{r}}$ and $\mu_{\mathrm{a}}$ were larger with a mask than without one, and there was an underadditive interaction between masking and repetition (i.e., $\left[\mu_{\mathrm{a}}-\mu_{\mathrm{r}}\right] \mid$ no mask $>\left[\mu_{\mathrm{a}}-\right.$ $\left.\mu_{\mathrm{r}}\right] \mid$ mask). Model $2+1$ fit the data significantly better than Model $2, F(1,34)=8.40, p<.01$. The improvement in goodness of fit was bought at the cost of violating Model 2's assumptions about repetition effects: $\mu_{\mathrm{r}}$ was greater than $\mu_{\mathrm{a}}$ both with and without a mask.

The models fit the data from individual subjects quite well, given the small amount of practice and the small number of observations per data point. Averaged across subjects and models, the correlation between observed and predicted values was .926, and the RMSD between observed and predicted values was $99 \mathrm{~ms}$. The mean values of the best-fitting parameters and the mean values of the measures of goodness of fit appear in Table 2. The standard errors of those means also appear in Table 2. The frequencies with which the ordinal predictions of each model were confirmed appear in Table 3.

Model 1 Constrained fit the data quite well, and the average parameter values were reasonable. The value of $\mu_{\mathrm{c}}$ was smaller with no mask than with a mask in 29 out of 32 subjects. Model 1 Unconstrained fit better. The correlation between observed and predicted values was higher for the unconstrained Model 1 in 32 out of 32 subjects, and the improvement in goodness of fit was significant at $p<.05$ in 7 of the 32 subjects. The improvement in fit was obtained at the cost of violating the assumptions of Model 1 , however. The estimate of mean switching time, $\mu_{\mathrm{s}}$, was greater with no mask than with a mask on average, $t(31)=3.45, p<.01$, and it was greater in 24 of 32 subjects $(p<.01$, by a binomial test).

Model 2 fit the data as well as Model 1 Unconstrained, which had the same number of parameters. The average parameter values were reasonable. The ordinal predictions were confirmed in nearly all of the subjects. Mean cue-encoding time was smaller on repetition trials than on alternation trials (i.e., $\mu_{\mathrm{r}}<\mu_{\mathrm{a}}$ ) in 32 of 32 subjects in both the no-mask and the mask conditions. Mean cue-encoding time was smaller with no mask than with a mask in 31 of 32 subjects on repetition trials and smaller in 28 of 32 subjects on alternation trials. The interaction contrast was negative in 25 of 32 subjects ( $p<.01$, by binomial test). In a 2 (repetition vs. alternation) $\times 2$ (no mask vs. mask) ANOVA on the cueencoding parameters, there were significant main effects of repetition, $F(1,31)=163.66, M S E=146,599.17$, and masking, $F(1$, $31)=69.60, M S E=31,447.62$, and the interaction between them was significant, $F(1,31)=16.91, M S E=3,855.37$, all $p s<.01$, consistent with Model 2's predictions.

Model 2+1 fit the data better than did Model 2. The correlation between observed and predicted values was higher for Model $2+1$ 
Table 2

Values (in ms) of Best-Fitting Parameters and Measures of Goodness of Fit for Fits of the Models to the Reaction Times Averaged Over Subjects (Ave) in Experiment 2 and Means (Mean) and Standard Errors of Values of Best-Fitting Parameters and Measures of Goodness of Fit for Fits of the Same Models to Individual Data From the 32 Subjects in Experiment 2

\begin{tabular}{|c|c|c|c|c|c|c|c|c|}
\hline & $\mathrm{RT}_{\text {Base }}$ & $\mu_{\mathrm{c}} \mid \mathrm{nm}$ & $\mu_{\mathrm{c}} \mid \mathrm{m}$ & $\mu_{\mathrm{s}}$ & & & $r$ & RMSD \\
\hline \multicolumn{9}{|c|}{ Model 1 Constrained } \\
\hline Ave & 705 & 406 & 664 & 314 & & & .989 & 34 \\
\hline Mean & 670 & 441 & 700 & 312 & & & .920 & 103 \\
\hline \multirow[t]{2}{*}{$S E$} & 24 & 28 & 31 & 22 & & & .005 & 3 \\
\hline & $\mathrm{RT}_{\text {Base }}$ & $\mu_{\mathrm{c}} \mathrm{nm}$ & $\mu_{\mathrm{c}} \mid \mathrm{m}$ & $\mu_{\mathrm{s}} \mid \mathrm{nm}$ & $\mu_{\mathrm{s}} \mid \mathrm{m}$ & & $r$ & RMSD \\
\hline \multicolumn{9}{|c|}{ Model 1 Unconstrained } \\
\hline Ave & 710 & 368 & 680 & 368 & 272 & & .993 & 29 \\
\hline Mean & 675 & 402 & 714 & 364 & 272 & & .927 & 98 \\
\hline \multirow[t]{2}{*}{$S E$} & 24 & 28 & 29 & 27 & 21 & & .005 & 3 \\
\hline & $\mathrm{RT}_{\text {Base }}$ & $\mu_{\mathrm{r}} \mid \mathrm{nm}$ & $\mu_{\mathrm{a}} \mid \mathrm{nm}$ & $\mu_{\mathrm{r}} \mathrm{m}$ & $\mu_{\mathrm{a}} \mid \mathrm{m}$ & & $r$ & RMSD \\
\hline \multicolumn{9}{|c|}{ Model 2} \\
\hline Ave & 654 & 443 & 757 & 744 & 973 & & .993 & 30 \\
\hline Mean & 621 & 470 & 789 & 777 & 1,006 & & .927 & 98 \\
\hline \multirow[t]{2}{*}{$S E$} & 26 & 33 & 37 & 32 & 36 & & .005 & 3 \\
\hline & $\mathrm{RT}_{\text {Base }}$ & $\mu_{\mathrm{r}} \mid \mathrm{nm}$ & $\mu_{\mathrm{a}} \mid \mathrm{nm}$ & $\mu_{\mathrm{r}} \mid \mathrm{m}$ & $\mu_{\mathrm{a}} \mid \mathrm{m}$ & $\mu_{\mathrm{s}}$ & $r$ & RMSD \\
\hline \multicolumn{9}{|c|}{ Model $2+1$} \\
\hline Ave & 685 & 402 & $61^{\mathrm{a}}$ & 709 & $304^{\mathrm{a}}$ & $677^{\mathrm{a}}$ & .994 & 26 \\
\hline Mean & 653 & 430 & 365 & 741 & 590 & 411 & .930 & 97 \\
\hline$S E$ & 25 & 31 & 51 & 31 & 66 & 60 & .005 & 3 \\
\hline
\end{tabular}

Note. $\quad \mathrm{RT}=$ reaction time; $\mu_{\mathrm{c}}=$ mean cue-processing time; $\mu_{\mathrm{s}}=$ mean set-switching time; $\mu_{\mathrm{r}}=$ mean cue-processing time on repetition trials; $\mu_{\mathrm{a}}=$ mean cue-processing time on alternation trials; $\mathrm{nm}=$ no mask on cue; $\mathrm{m}=$ mask on cue; $r=$ correlation between predicted and observed values; RMSD = root-mean-squared deviation between predicted and observed values.

${ }^{a}$ Outside the $95 \%$ confidence interval for the average parameter value from the fits to individual subject data.

in 27 of 32 subjects $^{3}$ and significant at $p<.05$ in 3 of them. However, the increase in goodness of fit was bought at the cost of implausible parameter values. On average, cue-encoding time was longer on repetition trials than on alternation trials with and without a mask (by 151 and $65 \mathrm{~ms}$, respectively). Cue-encoding time was longer on repetition trials in 16 of 32 subjects in the no-mask condition and in 18 of 32 subjects in the mask condition. In a 2 (repetition vs. alternation) $\times 2$ (no mask vs. mask) ANOVA on the cue-encoding parameters, there was a significant main effect of masking, $F(1,31)=72.41, p<.01, M S E=31,797.39$, and the interaction between repetition and masking was significant, $F(1,31)=14.98, p<.01, M S E=3,892.70$, consistent with Model 2+1's predictions. However, the main effect of repetition approached significance, $F(1,31)=3.36, p<.10, M S E=$ $111,605.93$, indicating slower cue-encoding times for repetition trials than for alternation trials, which is inconsistent with Model $2+1$ 's predictions.

The fits to individual subject data suggest that the fits to the average data should be viewed with caution. The parameter values that fit the average data differed substantially from the average parameter values that fit the individual data. For Model 1 Con- strained, Model 1 Unconstrained, and Model 2, the parameters from the average data were within the $95 \%$ confidence intervals of the average values from the fits to individual data, but for Model $2+1$, the values of cue-encoding time on alternation trials with and without a mask, $\mu_{\mathrm{a}} \mid \mathrm{nm}$ and $\mu_{\mathrm{a}} \mid \mathrm{m}$, were significantly smaller in the fits to the average data, and the value of set-switching time, $\mu_{\mathrm{s}}$, was significantly larger. Thus, the parameters that represent the average data may not represent the individual subjects' data very well. In this context, as in others, it is better to fit models to individual subjects than to data averaged over subjects.

\footnotetext{
${ }^{3}$ Technically, a nested model should never fit the same data set better than the model it is nested in. Model 2 is nested in Model $2+1$ in that Model $2+1$ reduces to Model 2 if set-switching time, $\mu_{\mathrm{s}}$, vanishes (i.e., if $\mu_{\mathrm{s}}$ vanishes, then Equation 8 becomes Equation 5). However, in fitting the models with the Excel Solver routine, it was necessary to constrain the values of the parameters to be greater than or equal to 1 , so from a mathematical perspective, the fitted models were not exactly nested. Consequently, Model 2+1 did not always fit the data as well as or better than Model 2.
} 
Table 3

Number of Subjects (Max = 32) Confirming Ordinal Predictions of Model 1 Constrained, Model 1 Unconstrained, Model 2, and Model 2+1 in Experiment 2

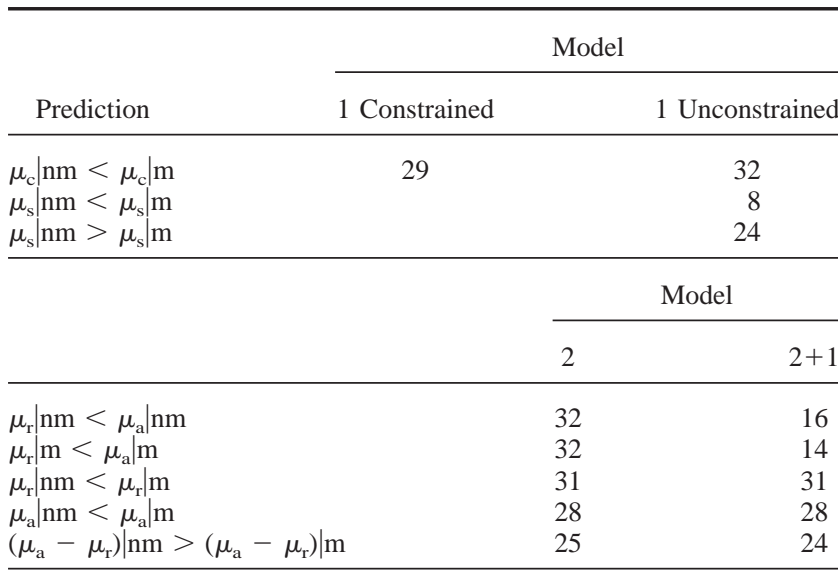

Note. $\operatorname{Max}=$ maximum; $\mu_{\mathrm{c}}=$ mean cue-processing time; $\mu_{\mathrm{s}}=$ mean set-switching time; $\mu_{\mathrm{r}}=$ mean cue-processing time on repetition trials; $\mu_{\mathrm{a}}=$ mean cue-processing time on alternation trials; $\mathrm{nm}=$ no mask on cue; $\mathrm{m}=$ mask on cue.

\section{Conclusions}

This experiment replicated standard effects in the explicit taskcuing procedure, and it replicated the pattern observed in Experiment 1 . The underadditive interaction between repetition and masking, which contradicts Model 1 and supports Model 2, appeared in the RT data and in the estimates of cue-encoding time for Model 2 in the fits to average data and in the fits to individual subjects. Model 1 Unconstrained was able to account for this interaction only by violating its assumption that set-switching time is unaffected by factors that prolong cue encoding. Model $2+1$ fit the data better than Model 2 but only by violating the assumption that cue encoding is faster on repetition trials than on alternation trials. Its best-fitting parameters suggested that cue-encoding time was faster on alternation trials than on repetition trials. As with Experiment 1, Model 2 provides the best account of the data, suggesting that the explicit task-cuing procedure does not involve set switching.

\section{Experiment 3}

The third experiment tested a new prediction that contrasted Models 1, 2, and 2+1. Model 1 predicts that the benefit of cue repetition stems from a savings in set-switching time; Model 2 predicts that the benefit of cue repetition stems from a savings in cue-encoding time; and Model $2+1$ predicts that the benefit of cue repetition reflects both types of savings. To contrast these predictions, we cued each task in two different ways. We used two tasks-magnitude and parity judgments of digits. We cued the magnitude task with a name cue - the word Magnitude that named the task-and with a mapping cue-the words High-Low that specified the mapping of judgments onto responses, which we used in Experiments 1 and 2. We cued the parity task with a name cue (the word Parity) and a mapping cue (the words Odd-Even) as well. With this procedure, three things could happen on successive trials: The cue could repeat (e.g., Magnitude $\rightarrow$ Magnitude), the task could repeat (e.g., Magnitude $\rightarrow$ High-Low), or the task could alternate (e.g., Magnitude $\rightarrow$ Odd-Even). Model 1 assumes that the benefit of cue repetition stems from task repetition, so it predicts the same benefit on task-repetition trials as on cuerepetition trials. Model 2 assumes that the benefit of cue repetition stems from encoding the same cue twice, so it predicts no benefit on task-repetition trials. Task-repetition trials should be as slow as task-alternation trials. Model $2+1$ assumes that the benefit of cue repetition reflects savings in both cue encoding and set switching, so it predicts more benefit on cue-repetition trials than on taskrepetition trials, and it predicts benefit on task-repetition trials relative to task-alternation trials.

We tested these predictions qualitatively by comparing mean RTs in the three conditions and quantitatively by fitting Models 1 , 2 , and $2+1$ to the data and evaluating their goodness of fit and the values of their best-fitting parameters.

\section{Method}

Subjects. The subjects were 32 students from an introductory psychology course who participated to fulfill course requirements. None had served in Experiment 1 or Experiment 2.

Apparatus and stimuli. The apparatus and stimuli were the same as in Experiment 2 (i.e., there were 10 SOAs: 0, 100, 200, 300, 400, 500, 600, 700, 800, and $900 \mathrm{~ms}$ ), except that there were four cues (Magnitude, High-Low, Parity, and Odd-Even) and eight targets (the digits 1, 2, 3, 4, $6,7,8$, and 9). Subjects responded by pressing the 4 key for high and odd digits and the 6 key for low and even digits.

Procedure. The basic design involved 4 (cues) $\times 8$ (targets) $\times 10$ $($ SOAs $)=320$ trials. The experiment involved two replications of the basic design, in an order randomized separately for each subject, for a total of 640 trials. Short breaks were allowed every 64 trials. In all other respects, the procedure was the same as in Experiment 2, except that subjects used the same keys ( 4 and 6 on the numeric keypad) for both tasks.

\section{Results and Discussion}

Standard analyses. Accuracy was high, averaging 95\%, and there was no suggestion of a speed-accuracy tradeoff, so the analyses focused on RT. RT data were sorted into cue-repetition, task-repetition, and task-alternation trials post hoc. The mean RTs in each cell of the 3 (cue repetition, task repetition, task alternation) $\times 10(\mathrm{SOA})$ design are presented in Figure 6 .

The data from cue-repetition and task-alternation trials replicated standard effects. RT decreased with SOA, and it was faster for cue repetitions $(M=784 \mathrm{~ms})$ than for task alternations $(M=$ $987 \mathrm{~ms}$ ). The difference between cue repetition and task alternation decreased as SOA increased. The theoretically important results concerned the task-repetition condition. Model 1 predicts that task-repetition RTs should resemble cue-repetition RTs, whereas Model 2 predicts that task-repetition RTs should resemble task-alternation RTs. The data were closer to the predictions of Model 2 than Model 1. Mean RTs for task repetitions ( $M=952$ $\mathrm{ms}$ ) were substantially slower than RTs for cue repetitions (difference $=168 \mathrm{~ms}$ ) and almost as slow as RTs for task alternations (difference $=35 \mathrm{~ms})$. Model $2+1$ predicts an advantage of cue repetition over task repetition and an advantage of task repetition over task alternation, so it is most consistent with the results. However, the 35-ms difference between task repetition and task alternation was quite small and appeared to increase rather than decrease with SOA. It may be an unrealistic estimate of setswitching time in unpracticed subjects. 


\section{- Cue Repetition \\ - Task Repetition \\ - Task Alternation}
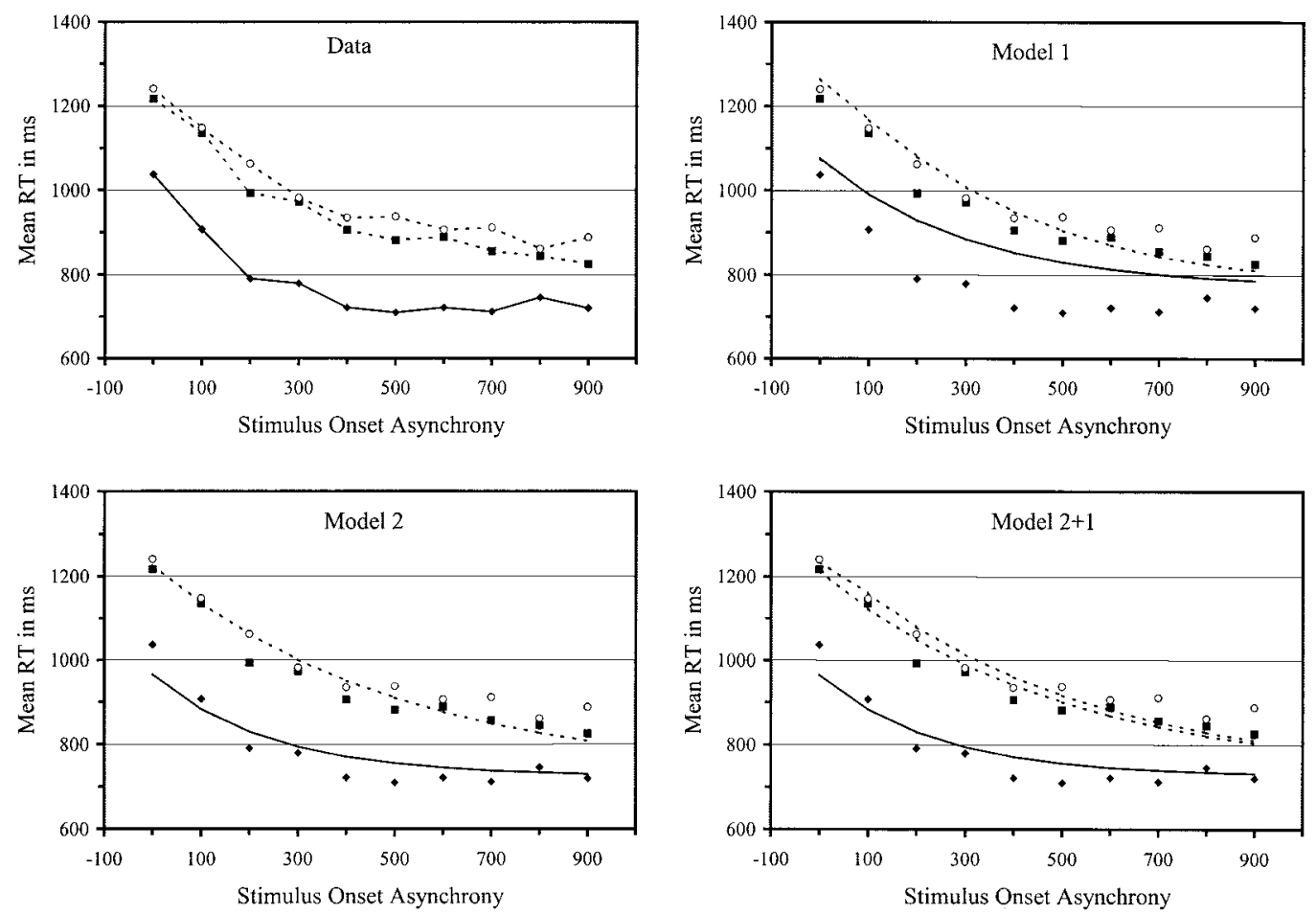

Figure 6. Mean reaction times (RTs) as functions of stimulus onset asynchrony in cue-repetition (filled diamonds, solid lines), task-repetition (filled squares, dashed lines), and task-alternation (open circles, dashed lines) conditions of Experiment 3. Top left panel: data points connected by lines. Remaining panels: points $=$ observed data; lines $=$ model predictions.

These conclusions were supported by a 3 (repetition type: cue repetition, task repetition, task alternation) $\times 10(\mathrm{SOA})$ ANOVA performed on the mean RTs. There were significant main effects of repetition type, $F(2,62)=90.58, p<.01, M S E=41,524.85$, and SOA, $F(9,279)=102.02, p<.01, M S E=13,414.83$, and a significant interaction between repetition type and SOA, $F(18$, $558)=2.17, p<.01, M S E=9,731.11$. Nonorthogonal comparisons showed that cue repetitions were significantly faster than task repetitions, $F(1,62)=108.75, p<.01, M S E=41,524.85$, and that task repetitions were significantly faster than task alternations, $F(1,62)=4.72, p<.05, M S E=41,524.85$.

The accuracy data were analyzed in a 3 (repetition type) $\times 10$ (SOA) ANOVA. The main effect of repetition type was significant, $F(2,62)=17.78, p<.01, M S E=36.86$, reflecting higher accuracy on repetition trials than on alternation trials. The main effect of SOA was also significant, $F(9,279)=2.39, p<.05$, $M S E=21.77$, reflecting higher accuracy with longer SOAs. The interaction between repetition and SOA was not significant. Nonorthogonal contrasts showed that the $96 \%$ accuracy in the cuerepetition condition was significantly higher than the $95 \%$ accuracy in the task-repetition condition, $F(1,62)=4.34, p<.05$, and the $95 \%$ accuracy in the task-repetition condition was significantly higher than the $93 \%$ accuracy in the task-alternation condition, $F(1,62)=8.68, p<.01$, both MSEs $=38.86$.
Model fitting. We fit Models 1, 2, and 2+1 to 30 mean RTs averaged over subjects and to the 30 mean RTs from the 32 individual subjects. Model 1 assumes no benefit from repeating the cue, so cue-repetition and task-repetition conditions were both fit using Equation 1 and task alternation was fit using Equation 2 (all conditions constrained to have the same value of $\mu_{\mathrm{c}}$ ). Model 2 assumes no set switching, so cue repetition was fit using Equation 4 and task repetition and task alternation were both fit using Equation 5 (constrained to have the same value of $\mu_{\mathrm{a}}$ for both conditions). Model $2+1$ assumes benefit from cue repetition and set switching on alternation trials, so cue repetition was fit using Equation 4, task repetition was fit using Equation 5, and task alternation was fit using Equation 8. The mean and standard errors of the parameter values and measures of goodness of fit are presented in Table 4.

The predicted RTs for the model fits to the data averaged across subjects are plotted along with the observed RTs in Figure 6. Model 1 did not fit the average data very well, compared to Models 2 and $2+1$. The correlation between observed and predicted values was substantially smaller, and RMSD was more than twice as large. Model 2+1 fit better than Model 2, but the improved fit for Model 2+1 was not significant and was bought at the cost of an unreasonably small value for the set-switching time parameter; $\mu_{\mathrm{s}}$ 
Table 4

Values (in ms) of Best-Fitting Parameters and Measures of Goodness of Fit for Fits of the Models to the Data Averaged Across Subjects (Ave) in Experiment 3 and Means (Mean) and Standard Errors of Values of Best-Fitting Parameters and Measures of Goodness of Fit for Fits of the Same Models to 32 Individual Subjects in Experiment 3

\begin{tabular}{|c|c|c|c|c|c|c|}
\hline & $\mathrm{RT}_{\text {Base }}$ & $\mu_{\mathrm{c}}$ & $\mu_{\mathrm{s}}$ & & $r$ & RMSD \\
\hline \multicolumn{7}{|c|}{ Model 1} \\
\hline Ave & 769 & 306 & 190 & & .844 & 78 \\
\hline Mean & 749 & 323 & 189 & & .712 & 122 \\
\hline \multirow[t]{2}{*}{$S E$} & 28 & 23 & 20 & & .018 & 5 \\
\hline & $\mathrm{RT}_{\text {Base }}$ & $\mu_{\mathrm{r}}$ & $\mu_{\mathrm{a}}$ & & $r$ & RMSD \\
\hline \multicolumn{7}{|c|}{ Model 2} \\
\hline Ave & 724 & 241 & 503 & & .971 & 35 \\
\hline Mean & 703 & 261 & 522 & & .804 & 101 \\
\hline \multirow[t]{2}{*}{$S E$} & 24 & 24 & 25 & & .016 & 4 \\
\hline & $\mathrm{RT}_{\text {Base }}$ & $\mu_{\mathrm{r}}$ & $\mu_{\mathrm{a}}$ & $\mu_{\mathrm{s}}$ & $r$ & RMSD \\
\hline \multicolumn{7}{|c|}{ Model $2+1$} \\
\hline Ave & 725 & 239 & 498 & $22^{\mathrm{a}}$ & .972 & 34 \\
\hline Mean & 705 & 258 & 493 & 47 & .816 & 98 \\
\hline$S E$ & 24 & 24 & 25 & 11 & .016 & 4 \\
\hline
\end{tabular}

Note. $\quad \mathrm{RT}=$ reaction time; $\mu_{\mathrm{c}}=$ mean cue-processing time; $\mu_{\mathrm{s}}=$ mean set-switching time; $\mu_{\mathrm{r}}=$ mean cue-processing time on repetition trials; $\mu_{\mathrm{a}}=$ mean cue-processing time on alternation trials; $r=$ correlation between predicted and observed values; RMSD = root-mean-squared deviation between predicted and observed values.

${ }^{\text {a }}$ Outside the $95 \%$ confidence interval of the mean parameter value across subjects.

for Model 2+1 was almost an order of magnitude smaller than $\mu_{\mathrm{s}}$ in Model 1.

The fits to the individual subject data were not as good as the fits to individual subjects in Experiment 2, but they were still good enough to be informative. Model 2 fit the data better than Model 1 on average and in 30 of the 32 subjects. Model $2+1$ fit the data better than Model 2 on average, but it only fit better in 17 of the 32 subjects. ${ }^{4}$ The improvement in fit was not significant in any subject. Moreover, the switching-time parameter in Model 2+1, $\mu_{\mathrm{s}}$, was unreasonably small. It was about one quarter of the value estimated in the fits of Model 1.

Again, the fits to the average data should be viewed with caution because the parameter values diverged somewhat from the average parameter values from the fits to individual subjects. The setswitching time parameter in Model 2+1 was outside the $95 \%$ confidence interval around the mean value from the fits to individual subjects. This underscores the point that models should be fit to individual subject data rather than to data averaged across subjects.

\section{Conclusions}

The contrast between cue-repetition and task-alternation trials replicated standard results. The difference was large at short SOAs and decreased as SOA increased. Task-repetition trials were more like task-alternation trials than cue-repetition trials, suggesting that cue-repetition effects account for most of the difference between repetition and alternation conditions. The fits of the models led to similar conclusions. Model 1 did not fit the data very well, either for individual subjects or averaged across subjects. It predicted no difference between cue repetitions and task repetitions, and the large observed difference contradicts that prediction. Model 2 fit individual subject and average data quite well. It predicted no difference between task repetitions and task alternations, and the small but significant difference between those conditions is inconsistent with that prediction. Model $2+1$ fit the data slightly better than Model 2, but the improvement in fit was not significant. Model 2+1 predicted the observed difference between cue repetitions and task repetitions and the observed difference between task repetitions and task alternations, and so it would appear to be most consistent with the data. However, the difference between task repetitions and task alternations, which reflects set-switching time, was quite small. The values of $\mu_{\mathrm{s}}$ required for the Model $2+1$ fits were very small. They were smaller than the values required to fit Model 1 to the same data and much smaller than the values required to fit Model 1 and Model $2+1$ to the data from Experiment 2. As in the previous experiments, Model 2+1's ability to account for the data is bought at the cost of implausible parameter values. Even if we accept Model $2+1$, the data suggest that the benefit from repetition is mostly due to the processes involved in encoding the cue rather than the processes involved in switching task sets. This conclusion challenges the idea that the explicit task-cuing procedure evokes an endogenous act of control.

\section{Experiment 4}

The fourth experiment was designed to replicate the comparison between cue repetition, task repetition, and task alternation with a different set of cues and tasks. We used tasks developed by Meiran (1996) that required subjects to judge the location of a happy face presented in one of four quadrants in a $2 \times 2$ grid. In one task, subjects judged vertical location, indicating whether the happy face appeared in the top two or bottom two quadrants-that is, above or below the horizontal line that ran through the center of the grid. In the other task, they judged whether the happy face appeared in the left two or right two quadrants-that is, left of or right of the vertical line that ran through the center of the grid. We used two different cues for each task: Above-Below and Horizontal for the first task and Left-Right and Vertical for the second.

As in Experiment 3, Model 1 predicts that cue repetitions and task repetitions will be equally fast and both will be faster than task alternations. Model 2 predicts that cue repetitions will be faster than task repetitions, which will not be faster than task alternations. Model $2+1$ predicts that cue repetitions will be faster than task repetitions, and task repetitions will be faster than task alternations. As in Experiment 3, we fit Models 1, 2, and 2+1 to the data averaged over subjects and to the individual data from each subject.

\footnotetext{
${ }^{4}$ Again, Model 2+1 did not always fit the data as well as or better than Model 2 because the version we fitted was constrained to have $\mu_{\mathrm{s}}$ greater than or equal to 1 . Truly nested versions of Models 2 and $2+1$ would allow $\mu_{\mathrm{s}}$ to vanish.
} 


\section{Method}

Subjects. We tested 32 graduate and undergraduate students and paid them $\$ 8$ for their participation. Two subjects had served in Experiment 1.

Apparatus and stimuli. The apparatus was the same as in the previous experiments. The cues and targets were different. Each trial began with a display containing a grid that was exposed for $500 \mathrm{~ms}$. The grid was $32 \mathrm{~mm}$ high and $38 \mathrm{~mm}$ wide. The vertical lines were $1 \mathrm{~mm}$ thick, and the horizontal lines were $0.8 \mathrm{~mm}$ thick. Then a cue was presented $6 \mathrm{~mm}$ above the grid. All cues were $5 \mathrm{~mm}$ high. Vertical was $24 \mathrm{~mm}$ wide, Left-Right and Horizontal were $31 \mathrm{~mm}$ wide, and Above-Below was $34 \mathrm{~mm}$ wide. After an SOA of 0, 100, 200, 300, 400, 500, 600, 700, 800, or $900 \mathrm{ms,} \mathrm{a}$ happy-face target appeared in the center of one of the four quadrants. It was made from the ASCII character 1 , and it was $5 \mathrm{~mm}$ high and $3 \mathrm{~mm}$ wide. The cue and the target were exposed until the subject responded, whereupon the display went blank for a 1,500-ms ITI. Responses were taken from the 1 and 9 or the 7 and 3 keys on the numeric keypad.

Procedure. The basic design involved 4 (cues) $\times 4$ (target locations) $\times 10($ SOAs $)=160$ trials. There were six replications of the basic design, for a total of 960 trials. The order in which the trials appeared was randomized separately for each subject. The mapping of stimuli onto responses was counterbalanced between subjects. Half of the subjects pressed the 1 key for "Below" and "Left" and the 9 key for "Above" and "Right." The other half pressed the 7 key for "Above" and "Left" and the 3 key for "Below" and "Right."

\section{Results and Discussion}

Standard analyses. Accuracy was high, averaging 96\%, and there was no suggestion of a speed-accuracy tradeoff, so the analyses focused on RT. Trials were divided post hoc into cue repetitions, task repetitions, and task alternations. The mean RTs in each cell of the 3 (repetition type: cue repetition, task repetition, task alternation) $\times 10(\mathrm{SOA})$ design are plotted in the top left panel of Figure 7.

RT decreased with SOA, and the difference between repetition conditions decreased as SOA increased. Averaged over SOA, RT was 109 ms faster for cue repetitions than for task alternations, replicating the standard effect. RT for task repetitions was $95 \mathrm{~ms}$ slower than RT for cue repetitions and only 14 ms faster than RT for task alternations, suggesting that the bulk of the difference between cue repetition and task alternation is due to repetition benefits in cue encoding.

These conclusions were supported in a 3 (repetition type) $\times 10$ (SOA) ANOVA on the mean RTs. The main effects of repetition type, $F(2,62)=69.88, p<.01, M S E=16,014.07$, and SOA, $F(9$, 279) $=200.96, p<.01, M S E=5,564.38$, were significant, and the interaction between them was significant, $F(18,558)=4.56$, $p<.01, M S E=4,992.80$. Nonorthogonal contrasts showed that the difference between cue repetitions and task repetitions was
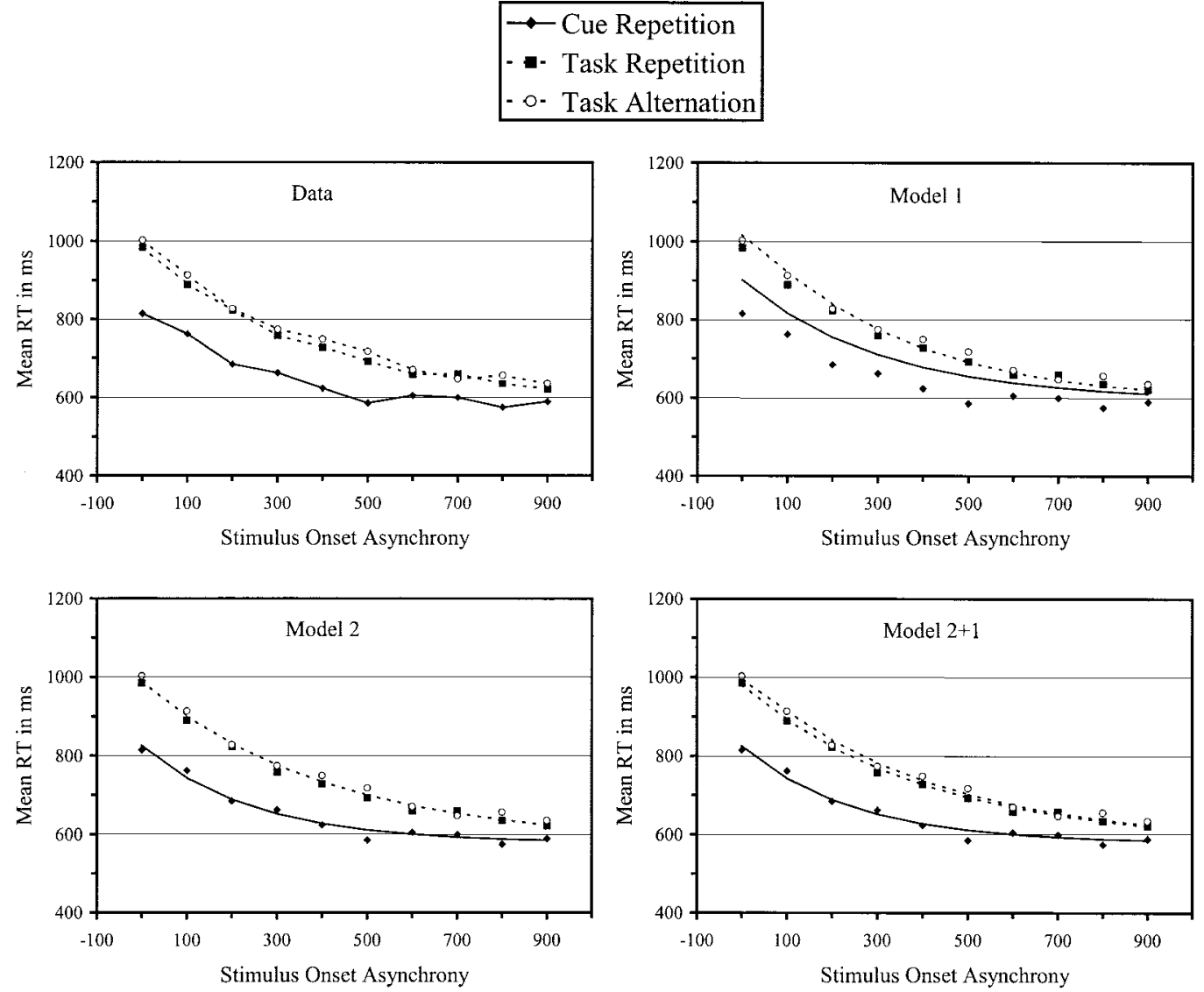

Figure 7. Mean reaction times (RTs) as functions of stimulus onset asynchrony in cue-repetition, taskrepetition, and task-alternation conditions of Experiment 4. Top left panel: data points connected by lines. Remaining panels: points $=$ observed data; lines $=$ model predictions. 
significant, averaged over SOA, $F(1,62)=90.17, p<.01$, but the difference between task repetitions and task alternations was not, $F(1,62)=1.96$.

We performed a 3 (repetition type) $\times 10(\mathrm{SOA})$ ANOVA on the accuracy data. The main effect of repetition type was significant, $F(2,62)=12.73, p<.01, M S E=27.33$, as was the main effect of SOA, $F(9,279)=2.27, p<.05, M S E=13.09$. The interaction between repetition type and SOA was not significant, $F(18$, $414)=1.36, M S E=13.04$. Nonorthogonal contrasts showed that the $97 \%$ accuracy in the cue-repetition condition was significantly higher than the $96 \%$ accuracy in the task-repetition condition, and the $96 \%$ accuracy in the task-repetition condition was significantly higher than the $95 \%$ accuracy in the task alternation condition, both $F \mathrm{~s}(1,62)=5.85, p<.05, M S E=27.33$.

Model fitting. We fit Model 1 to the mean RTs using Equation 1 for cue repetition and task repetition and Equation 2 for task alternation. We fit Model 2 to the mean RTs using Equation 4 for cue repetition and Equation 5 for task repetition and task alternation. We fit Model $2+1$ to the mean RTs using Equation 4 for cue repetition, Equation 5 for task repetition, and Equation 8 for task alternation. We fit all three models to the 30 mean RTs averaged over subjects and to the 30 mean RTs from individual subjects. The mean and standard errors of the parameter values and measures of goodness of fit are presented in Table 5.

The predicted RTs for the model fits to the data, averaged across subjects, are plotted along with the observed RTs in Figure 7.

Table 5

Values (in ms) of Best-Fitting Parameters and Measures of Goodness of Fit for Fits of the Models to the Data Averaged Across Subjects (Ave) in Experiment 4 and Means (Mean) and Standard Errors of Values of Best-Fitting Parameters and Measures of Goodness of Fit for Fits of the Same Models to 32 Individual Subjects in Experiment 4

\begin{tabular}{|c|c|c|c|c|c|c|}
\hline & $\mathrm{RT}_{\text {Base }}$ & $\mu_{\mathrm{c}}$ & $\mu_{\mathrm{s}}$ & & $r$ & RMSD \\
\hline \multicolumn{7}{|c|}{ Model 1} \\
\hline Ave & 594 & 307 & 116 & & .925 & 44 \\
\hline Mean & 587 & 316 & 117 & & .806 & 77 \\
\hline \multirow[t]{2}{*}{$S E$} & 27 & 19 & 14 & & .018 & 5 \\
\hline & $\mathrm{RT}_{\text {Base }}$ & $\mu_{\mathrm{r}}$ & $\mu_{\mathrm{a}}$ & & $r$ & RMSD \\
\hline \multicolumn{7}{|c|}{ Model 2} \\
\hline Ave & 578 & 248 & 411 & & .995 & 11 \\
\hline Mean & 572 & 257 & 422 & & .864 & 65 \\
\hline \multirow[t]{2}{*}{$S E$} & 26 & 19 & 18 & & .015 & 4 \\
\hline & $\mathrm{RT}_{\text {Base }}$ & $\mu_{\mathrm{r}}$ & $\mu_{\mathrm{a}}$ & $\mu_{\mathrm{s}}$ & $r$ & RMSD \\
\hline \multicolumn{7}{|c|}{ Model 2+1 } \\
\hline Ave & 579 & 246 & 401 & 14 & .996 & 10 \\
\hline Mean & 574 & 254 & 404 & 30 & .874 & 63 \\
\hline$S E$ & 26 & 18 & 18 & 10 & .013 & 4 \\
\hline
\end{tabular}

Note. $\quad \mathrm{RT}=$ reaction time; $\mu_{\mathrm{c}}=$ mean cue-processing time; $\mu_{\mathrm{s}}=$ mean set-switching time; $\mu_{\mathrm{r}}=$ mean cue-processing time on repetition trials; $\mu_{\mathrm{a}}=$ mean cue-processing time on alternation trials; $r=$ correlation between predicted and observed values; RMSD = root-mean-squared deviation between predicted and observed values.
Models 2 and $2+1$ fit the average data very well. The improvement in fit from Model 2 to Model $2+1$ was very small but significant statistically, $F(1,27)=6.74, p<.05$. Moreover, the switching-time parameter in Model $2+1$ was unreasonably small (14 ms). Model 1 did not fit the average data as well as Models 2 and $2+1$. The correlation between observed and predicted values was smaller, and RMSD was more than four times as large.

As before, the fits to individual subjects were not as good as the fits to the data averaged across subjects, but the pattern was the same. The best-fitting parameters for the fits to the average data were close to the average of the best-fitting parameters of the fits to individual subject data for all three models. The average correlation between observed and predicted values was higher for Model 2+1 than for Model 2, but it was larger in only 18 of the 32 subjects. ${ }^{5}$ The average correlation was higher for Model 2 than for Model 1, and it was larger in 29 of the 32 subjects.

\section{Conclusions}

Cue repetitions were faster than task alternations, replicating results from Experiment 3 and standard results in the literature. Task repetitions were much slower than cue repetitions and nearly as slow as task alternations, replicating results from Experiment 3. These results suggest that benefit from cue repetition accounts for most of the difference between cue repetitions and task alternations and that set switching, if it occurs at all, accounts for very little of the difference. The model fits led to similar conclusions. Model 1 did not fit the average data or the individual subject data as well as Model 2, and Model $2+1$ did not fit the average data or the individual subject data much better than Model 2. Model 2, which assumes no endogenous act of control in the explicit taskcuing procedure, provides the best account of the data.

\section{Experiment 5}

Experiments 1-4 used a constant, 500-ms interval between the subject's response and the appearance of the warning signal for the next trial. The constant ITI resulted in a correlation between SOA and the interval between successive targets. Thus, it is possible that the effects we have attributed to SOA are due to the interval between successive targets instead (cf. Allport et al., 1994). This issue has been raised in the literature before, and researchers have established that SOA has effects independent of ITI (e.g., Logan \& Zbrodoff, 1982; Meiran, 1996), but it is important to determine the extent to which the SOA effects in Experiments 1-4 were due to the interval between successive targets. Experiment 5 was conducted to address this issue. Subjects made magnitude and parity judgments about digits, and ITI and SOA were varied independently. There were three values of ITI $(250,500$, and $1,000 \mathrm{~ms})$ and 10 values of SOA $(0,100,200,300,400,500,600,700,800$, and $900 \mathrm{~ms}$ ).

\section{Method}

Subjects. Thirty-two subjects from the general university population were paid for participating in a single session. None had served in Experiments $1-4$.

\footnotetext{
${ }^{5}$ Model $2+1$ did not always fit the data as well as or better than Model 2 because our fitting routine did not allow $\mu_{\mathrm{s}}$ to vanish.
} 
Apparatus and stimuli. The apparatus and stimuli were the same as those used in Experiments 1-3. There were two cues, High-Low and Odd-Even, and eight targets, the digits $1,2,3,4,6,7,8$, and 9. Responses were collected from the 4 and 6 keys on the numeric keypad. There were three ITIs: 250,500 , and 1,000 ms. There were 10 SOAs $(0,100,200,300$, 400, 500, 600, 700, 800, and $900 \mathrm{~ms}$ ).

Procedure. The basic design involved 2 (cues) $\times 8$ (targets) $\times 3$ $($ ITIs $) \times 10(\mathrm{SOAs})=480$ trials. The experiment consisted of two replications of the basic design, for a total of 960 trials. Subjects were allowed short breaks every 96 trials. In all other respects, the procedure was the same as in Experiments 1-3.

\section{Results and Discussion}

Standard analyses. Accuracy was high, averaging 97\%, and there was no evidence of a speed-accuracy tradeoff, so the analyses focused on RT. Trials were divided into repetitions and alternations post hoc. The means across subjects for each combination of repetition and alternation and ITI are plotted as a function of SOA in Figure 8.

Standard effects were replicated at each ITI. RT was faster for repetitions than for alternations, RT decreased as SOA increased, and the difference between repetitions and alternations decreased as SOA increased. ITI had small effects compared to SOA, and these occurred primarily on alternation trials. On repetition trials, mean RT was 715, 714, and $721 \mathrm{~ms}$ for ITI $=250,500$, and 1,000, respectively. On alternation trials, mean RT was 816,807 , and 787 $\mathrm{ms}$ for ITI $=250,500$, and 1,000 , respectively. This suggests that the effects of SOA in the previous experiments were due to processes that intervened between the cue and the target (e.g., cue encoding and, possibly, set switching) rather than processes intervening between successive targets (cf. Allport et al., 1994; Logan \& Zbrodoff, 1982; Meiran, 1996).

Support for these conclusions was sought in a 2 (repetition vs. alternation $) \times 3($ ITI $) \times 10($ SOA $)$ ANOVA on the mean RTs. There were strong main effects of repetition, $F(1,31)=149.51$, $p<.01, M S E=24,595.39$, and SOA, $F(9,279)=184.62, p<$ $.01, M S E=7,641.74$, and a strong interaction between repetition and SOA, $F(9,279)=11.50, p<.01, M S E=5,963.71$. The main effect of ITI was significant but weak, $F(2,62)=3.64, p<.05$,

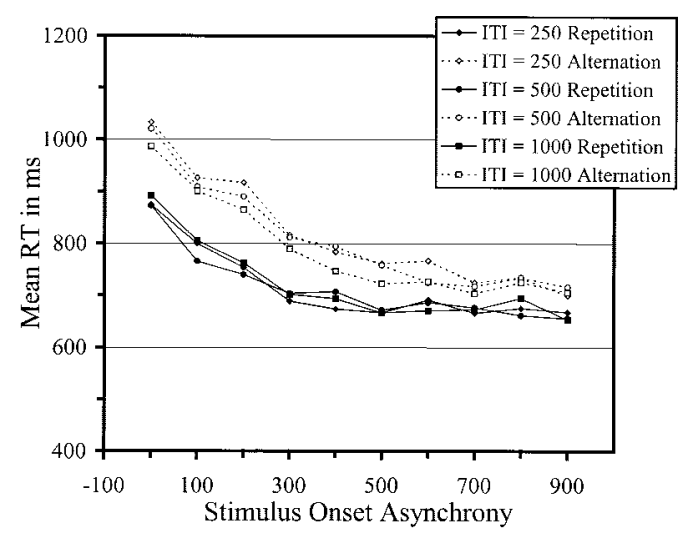

Figure 8. Mean reaction times (RTs) as functions of stimulus onset asynchrony for task repetitions (solid lines) and task alternations (dashed lines) at the 250-ms, 500-ms, and 1,000-ms intertrial intervals (ITIs) in Experiment 5 .
$M S E=6,969.30$, and ITI interacted significantly with repetition, $F(2,62)=7.07, p<.01, M S E=6,846.41$, but with nothing else.

The accuracy data were subjected to a 2 (repetition vs. alternation $) \times 3($ ITI $) \times 10(\mathrm{SOA})$ ANOVA. It yielded significant main effects of repetition, $F(1,31)=39.15, p<.01, M S E=29.86$, and SOA, $F(9,279)=4.51, p<.01, M S E=20.52$, and a significant interaction between repetition and SOA, $F(9,279)=2.11, p<$ $.05, M S E=21.88$. None of the effects involving ITI were significant.

Model fitting. We fit Models 1 and 2 to the 20 mean RTs in each ITI condition. As before, we fit the data averaged over subjects, and we fit the data from individual subjects. We used Equations 1 and 2 to fit Model 1 and Equations 4 and 5 to fit Model 2. The values of the best-fitting parameters and measures of goodness of fit for the fits to the average data and the means and standard errors of the values of the best-fitting parameters and measures of goodness of fit for the fits to individual subjects are presented in Table 6.

The observed and predicted RTs from the model fitting are plotted in Figure 9. The models fit the average data rather well. The mean correlation between observed and predicted RTs was .982, and the mean RMSD was 18 ms. Model 2 fit better than Model 1. For Model 2, the mean correlation was .987, and the mean RMSD was 15 ms. For Model 1, the mean correlation was .976 , and the mean RMSD was $21 \mathrm{~ms}$.

The fits to the individual subject data were not as good as the fits to the average data. Model 2 fit better than Model 1 in 23, 23, and 20 out of 32 subjects for ITI $=250,500$, and 1,000 ms, respectively. The differences at the 250- and 500-ms ITIs were significant ( $p<.05$, by a binomial test). In this experiment, the parameters for the fits to the average data were similar to the mean of the parameters for the fits to the individual subject data. None of the parameters for the average data fell outside the $95 \%$ confidence intervals of the mean parameters from the individual fits.

To determine whether the parameters were affected by ITI, we ran one-way ANOVAs on each parameter, with ITI as the effect. For Model 1, there was no effect of ITI on $\mathrm{RT}_{\text {Base }}, F(1,31)<1.0$, and no effect of ITI on cue-encoding time, $\mu_{\mathrm{c}}, F(1,31)=1.54$, $M S E=4,370.62$. ITI had a significant effect on set-switching time, $\mu_{\mathrm{s}}, F(1,31)=10.46, p<.01, M S E=4,113.70$; setswitching time decreased as ITI increased. For Model 2, there was no effect of ITI on $\mathrm{RT}_{\text {Base }}, F(1,31)<1.0$, or on $\mu_{\mathrm{r}}, F(1,31)<1.0$, but $\mu_{\mathrm{a}}$ decreased significantly as ITI increased, $F(1,31)=5.26$, $p<.01, M S E=5,852.92$.

\section{Conclusions}

The main purpose of this experiment was to determine whether ITI had a substantial effect on performance in our version of the explicit task-cuing task. Experiments 1-4 held ITI constant, so SOA was confounded with the interval between successive targets (see Allport et al., 1994; Logan \& Zbrodoff, 1982; Meiran, 1996). The results of Experiment 5 suggest that ITI has much smaller effects than SOA in our procedure, so it seems safe to conclude that the effects of SOA in Experiments 1-4 were due primarily to processes intervening between the cue and the target (i.e., cue encoding and, possibly, set switching). 
Table 6

Values (in ms) of the Best-Fitting Parameters and Measures of Goodness of Fit for Fits of the Models to the Data for Each Intertrial Interval (ITI) Averaged Across Subjects (Ave) in Experiment 4 and Means (Mean) and Standard Errors of Values of Best-Fitting Parameters and Measures of Goodness of Fit for Fits of the Same Models to 32 Individual Subjects in Experiment 5

\begin{tabular}{lrrrrr}
\hline & \multicolumn{5}{c}{ Model 1 } \\
\cline { 2 - 6 } ITI & $\mathrm{RT}_{\text {Base }}$ & $\mu_{\mathrm{c}}$ & $\mu_{\mathrm{s}}$ & $r$ & RMSD \\
\hline 250 & & & & & \\
Ave & 681 & 180 & 201 & .974 & 23 \\
Mean & 673 & 187 & 195 & .812 & 68 \\
SE & 19 & 14 & 14 & .020 & 4 \\
500 & & & & & \\
Ave & 685 & 167 & 193 & .977 & 21 \\
Mean & 674 & 177 & 189 & .806 & 68 \\
SE & 17 & 14 & 16 & .018 & 4 \\
1,000 & & & & & \\
Ave & 678 & 201 & 132 & .979 & 19 \\
Mean & 670 & 206 & 129 & .781 & 66 \\
$S E$ & 20 & 13 & 13 & .029 & 4 \\
\hline & & & Model 2 & & \\
& & & & & \\
\cline { 2 - 6 } & & & & & \\
\hline Base & $\mu_{\mathrm{r}}$ & $\mu_{\mathrm{a}}$ & $r$ & $\mathrm{RMSD}$ \\
\hline Ave & 666 & 201 & 372 & .987 & 16 \\
Mean & 659 & 206 & 376 & .820 & 67 \\
SE & 20 & 15 & 17 & .020 & 4 \\
500 & & & & & \\
Ave & 671 & 187 & 351 & .989 & 14 \\
Mean & 662 & 197 & 359 & .812 & 67 \\
SE & 17 & 14 & 17 & .018 & 4 \\
1,000 & & & & & \\
Ave & 666 & 215 & 327 & .986 & 15 \\
Mean & 659 & 218 & 316 & .784 & 65 \\
$S E$ & 20 & 14 & 19 & .029 & 4 \\
\hline & & & & & \\
\hline
\end{tabular}

Note. $\mathrm{RT}=$ reaction time; $\mu_{\mathrm{c}}=$ mean cue-processing time; $\mu_{\mathrm{s}}=$ mean set-switching time; $\mu_{\mathrm{r}}=$ mean cue-processing time on repetition trials; $\mu_{\mathrm{a}}=$ mean cue-processing time on alternation trials; $r=$ correlation between predicted and observed values; RMSD = root-mean-squared deviation between predicted and observed values.

\section{General Discussion}

The experiments replicated standard effects found with the explicit task-cuing procedure. RT was faster for cue repetitions than for task alternations, and the difference between repetition and alternation trials decreased as SOA increased. The main question addressed was whether this effect reflected an endogenous act of control that was evoked by the cue on task-alternation trials. The interactions between repetition and masking the cue in Experiments 1 and 2 and the large advantage of cue repetitions over task repetitions in Experiments 3 and 4 suggest that cue-encoding processes contribute much to the difference between repetitions and alternations. Experiment 5 showed that the SOA effects in Experiments 1-4 were due to processes intervening between the cue and the target rather than processes intervening between successive targets (cf. Allport et al., 1994; also see Logan \& Zbrodoff, 1982; Meiran, 1996). The modeling analyses in each experiment showed that a model that assumes only benefit from cue repetitions and no endogenous act of control (Model 2) accounts for the data quite well, quantitatively and qualitatively. A model that assumes only an act of control (Model 1) does not account for the data as well. A model that includes cue-encoding benefits and an act of control (Model 2+1) accounts for the data well quantitatively but yields parameter values that violate the assumptions of the model. On balance, the data provide more support for Model 2 than for Model 1 or Model $2+1$, suggesting that the explicit task-cuing procedure does not necessarily evoke an endogenous act of control (cf. Goschke, 2000; Mayr \& Keele, 2000; Mayr \& Kliegl, 2000; Meiran, 1996; Sudevan \& Taylor, 1987).

\section{Limitations}

Aspects of the present experimental design may limit these conclusions. We used a small number of stimuli $(3$ cues and 16 targets in Experiments 1 and 2; 4 cues and 8 targets in Experiment 3; 4 cues and 4 targets in Experiment 4; 2 cues and 8 targets in Experiment 5) and a small number of responses ( 6 in Experiments 1 and 2; 2 in Experiments 3-5) so subjects could learn the mapping between cues, targets, and responses and adopt the compoundstimulus strategy (i.e., Model 2). If the set of cues, targets, or responses was larger, subjects might not be able to learn the compound-stimulus strategy, particularly in the course of a singlesession experiment. A larger set of cues, targets, or responses may force subjects to adopt the strategy of switching task sets in response to the cue (i.e., Model 1 or Model 2+1). The limits of the compound-stimulus strategy remain to be discovered in future research.

The present conclusions are limited to the explicit task-cuing procedure. In this procedure, the stimuli presented on an individual trial provide enough information to uniquely specify a response. Other procedures for studying task switching, such as the taskalternation procedure (Allport et al., 1994; Jersild, 1927) and the alternating-runs procedure (Rogers \& Monsell, 1995), do not provide enough information to specify a unique response on each trial, so they may require an endogenous act of control. For example, they both require the subject to remember or retrieve the task to be performed on the current stimulus, and this may be viewed as an endogenous act of control (Goschke, 2000; Mayr \& Kliegl, 2000; Rubinstein et al., 2001).

Experiments 1 and 2 may be limited because subjects used keys on different rows of the numeric keypad to respond to the different tasks. They used the 7 and 9 keys for the High-Low task, the 4 and 6 keys for the Odd-Even task, and the 1 and 3 keys for the Digit-Word task. This assignment of tasks to keys required subjects to move their hands from one row to another on alternation trials but not on repetition trials. To determine whether hand movements affected our conclusions, we replicated Experiments 1 and 2, requiring subjects to press the same keys ( 4 and 6 ) for all three tasks. We found essentially the same results. The difference between repetition and alternation was smaller in the replications than in the original experiments, but the pattern of the data and the model fits was essentially the same. The only striking difference was that one of the subjects in the replication of Experiment 1 showed a slightly overadditive interaction between repetition and masking, which is consistent with Model 1. However, that subject had the slowest RTs, the highest error rates, and the worst model fits of the 3 subjects in the replication. Even for the best-fitting model, this subject's RMSD was 1.5 times as large as the RMSDs 


\section{$\rightarrow-$ Repetition \\ - 口- Alternation}
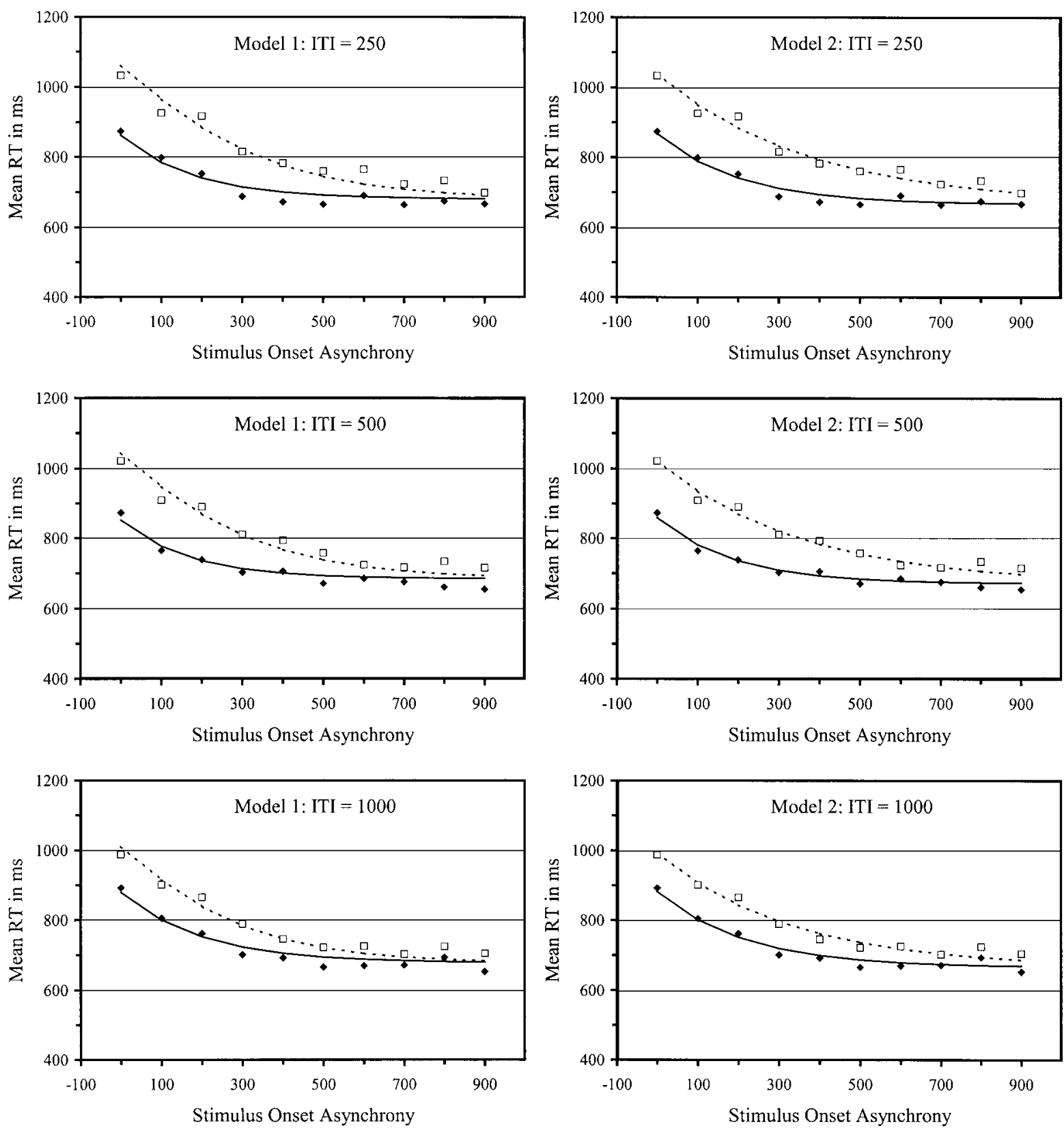

Figure 9. Mean predicted and observed reaction times (RTs) for repetition and alternation for each intertrial interval (ITI; in ms) in Experiment 5.

for the other subjects. Note that an overadditive interaction between repetition and masking is possible under some parameterizations of Model 2, so this subject's data are not inconsistent with Model 2. The replication of Experiment 2 was almost perfect in terms of the interactions and model fits. The best-fitting parameters of Model 1 Unconstrained and Model 2+1 violated the assumptions of the models, just as they did in the original Experiment 2 . Thus, the use of different keys for different tasks was not responsible for the pattern of results we observed.

\section{Relations to the Literature}

The models we propose address cue encoding and set switching explicitly but remain mute on other processes that may contribute to differences between repetition and alternation trials. For example, Allport et al. (1994) argued that previous task sets persist from one trial to the next and interfere with processing the target. Allport and Wylie (2000; Wylie \& Allport, 2000) argued that the target retrieves responses associated with it in the past, and these 
may interfere with target processing if the retrieved responses are incompatible with the required ones. Meiran $(1996,2000)$ argued that switching costs depend on interactions between stimulus task sets and response task sets for the alternative tasks. In principle, it should be possible to accommodate these effects in our models by allowing $\mathrm{RT}_{\mathrm{Base}}$ to vary between repetition and alternation conditions. $\mathrm{RT}_{\mathrm{Base}}$ reflects target encoding and response selection, among other things, and it may account for factors other than cue encoding and set switching. Our models could be viewed as special cases that are nested within these more general models. Future research will be required to assess the generality of our models.

The models we propose ignored the idea of residual switch costs, which has received much attention in the literature. Several investigators have found substantial differences between repetition and alternation trials at the longest SOAs or intertrial intervals in their experiments (e.g., Allport et al., 1994; De Jong, 2000; Goshcke, 2000; Rogers \& Monsell, 1995). The SOAs or intertrial intervals were so long that the researchers concluded that set switching must be "complete," yet some difference between repetition and alternation trials remained. These residual switch costs are important theoretically. Some investigators interpret them as evidence against an endogenous act of control (Allport et al., 1994; Goschke, 2000). Other investigators interpret them in terms of incomplete preparation, some arguing that not all acts of control can be completed in advance of the target stimulus (Mayr \& Keele, 2000; Rogers \& Monsell, 1995), others arguing that response preparation cannot be optimal (Meiran, 2000), and still others arguing that subjects do not try to prepare in advance on every trial (De Jong, 2000).

On the one hand, it should be possible to account for residual switch costs in the models we proposed by letting $\mathrm{RT}_{\text {Base }}$ vary between repetition and alternation conditions. This ploy would diminish the value of Equation 3 in estimating set-switching time. Set-switching time equals the difference between alternation and repetition $\mathrm{RT}$ at $\mathrm{SOA}=0$ only if $\mathrm{RT}_{\mathrm{Base}}$ is the same for alternation and repetition trials. Many of the factors that may cause residual switch costs would seem to affect $\mathrm{RT}_{\text {Base }}$ on alternation trials, in which case Equation 3 would overestimate set-switching time. It is also possible that some factors could affect $\mathrm{RT}_{\text {Base }}$ on repetition trials, and in some conditions, $\mathrm{RT}_{\mathrm{Base}}$ may be larger on repetition trials than on alternation trials. In those conditions, Equation 3 would underestimate set-switching time. Fortunately, our models provide a way around this problem. Set-switching time can be estimated independent of $\mathrm{RT}_{\text {Base }}$ by applying Equation 2 or Equation 8 to the time-course function for alternation trials.

On the other hand, it may be possible to account for the appearance of residual switch costs without varying $\mathrm{RT}_{\text {Base }}$ between repetition and alternation conditions. We obtained good fits in the present experiments assuming that there were no residual switch costs (i.e., assuming that $\mathrm{RT}_{\text {Base }}$ was the same on repetition and alternation trials). The fits to the data from Experiments 2 and 3 are particularly relevant. There were substantial differences between repetition and alternation trials at the longest $(900 \mathrm{~ms}$ ) SOA, yet the models assumed that the difference between repetition and alternation vanished at asymptote.

The evaluation of residual switch costs depends on what it means for cue-encoding and set-switching processes to be "complete." Residual switch costs are defined as the difference between repetition and alternation RT that remains when set switching is "complete," but the meaning of "complete" has not been specified in the literature. Our models provide a specific meaning. They treat cue encoding and set switching as stochastic processes, in that the time at which they are complete varies randomly from trial to trial. The parameters $\mu_{\mathrm{c}}$ and $\mu_{\mathrm{s}}$ reflect mean finishing time- that is, the time at which the processes are complete on average. The timecourse function reflects the cumulative distribution of finishing times. The asymptote of the time-course function reflects the asymptote of the cumulative distribution function, which in theory occurs when SOA becomes infinite. In practice, the asymptotic completion time may be estimated from the maximum completion time, which is much longer than the mean completion time, particularly if the distributions of cue-encoding time and setswitching time are skewed like RT distributions. Thus, it is possible that in many studies of residual switch costs, cue encoding and set switching are not complete on a substantial proportion of the trials, even at the longest SOA or intertrial interval (cf. De Jong, 2000). Future research will be necessary to determine whether or not this is the case. Such research will require a formal model of the time course of cue encoding and set switching to estimate the distribution of completion times to determine whether these processes are complete. Perhaps our models will be useful in those endeavors.

\section{Modeling Executive Control}

We have treated the models as alternatives that compete with each other to provide mutually exclusive accounts of the data. From this perspective, Model 2 is superior to Model 1 in that it captures the interaction between repetition and masking observed in Experiments 1 and 2 and the difference between cue repetition and task repetition observed in Experiments 3 and 4. Model 2 is superior to Model $2+1$ because it accounts for these effects without requiring parameter values that contradict its assumptions. However, it is possible to view the models differently, as members of a family that may be applied to data sets to measure cueencoding and set-switching times.

From this perspective, Model $2+1$ is the general case, Model 1 is a special limiting case in which cue-encoding time is independent of cue repetition, and Model 2 is a special limiting case in which set-switching time equals zero. The general model can be fitted to the data by adding constraints to the fitting program that are implied by the assumptions of the special cases. That is, Model $2+1$ can be fitted to the data with the constraint that $\mu_{\mathrm{r}} \leq \mu_{\mathrm{a}}$ with and without a mask, and $\mu_{\mathrm{c}} \mid$ no mask $\leq \mu_{\mathrm{c}} \mid$ mask for repetitions and alternations. Indeed, we tried fitting Model $2+1$ to the data from Experiments 1 and 2 with these constraints and found that the reduction in goodness of fit was quite small. The advantage of this general-case/special-case perspective is that it allows us to measure cue-encoding time and set-switching time and use those measures to answer other questions about executive control. For example, the measures could be used in investigations of residual switching times to determine the expected proportion of trials on which set switching is complete for a given SOA.

An important goal for future development is to specify the processes that contribute to $\mathrm{RT}_{\text {Base }}$. This goal is important for several reasons, some of which are outlined above. Perhaps the most important reason is to ground our theory of executive processing in a theory of subordinate processing. It is difficult to say whether a task involves an endogenous act of control without knowing what the act of control does and what processes it acts on. 
We have begun to ground our theory of executive control in Bundesen's (1990, 1998a, 1998b) TVA model of attention (see also Logan, 2002). Logan and Gordon (2001) proposed a theory called Executive Control of TVA (ECTVA) in which executive processes control TVA. TVA has bias and priority parameters that Bundesen (1990) assumed were controlled by an intelligent agent. ECTVA was intended to provide a theory of that intelligent agent. In ECTVA, a task set is a set of bias and priority parameters that is sufficient to program TVA to perform a given task. Task switching involves deriving a set of TVA parameters from instructions or retrieving them from memory and then instantiating them in TVA. In principle, the tasks we investigated in the present experiments could be modeled in TVA, grounding our current models in TVA and constraining the values of $\mathrm{RT}_{\text {Base }}$ in a variety of conditions (see Logan \& Gordon, 2001).

Other investigators have begun to ground models of executive control in architectures other than ECTVA. Kieras, Meyer, Ballas, and Lauber (2000) provided models of executive control with the executive process interactive control formalism (also see Meyer \& Kieras, 1997). Gilbert and Shallice (2002) provided a model of executive control within the parallel distributed processing framework, extending Cohen, Dunbar, and McClelland's (1990) model of the Stroop task to set-switching situations. Byrne and Anderson (2001) and Sohn and Anderson (2001) applied the adaptive control of thought-rational model to executive phenomena in dual-task and task-switching situations. The cue-encoding and set-switching models we proposed in this article could also be instantiated in these architectures to ground them more completely and constrain them even further. This would allow researchers to develop more precise hypotheses about executive control and to test them more rigorously.

\section{Conclusions}

The present experiments suggest that the difference between repetition and alternation trials in the explicit task-cuing procedure does not necessarily reflect an endogenous act of control. Like Pfungst (1907, 1911), we have shown that the homunculus may not be so clever, or at least that its cleverness may not be responsible for the difference between repetition and alternation trials in the explicit task-cuing procedure. Simpler psychological processes that give rise to benefits from repeating the cue seem sufficient to explain the observed difference. Following Pfungst's example, we urge caution in attributing behavioral effects to acts of control by a clever homunculus. We do not doubt the existence of an intelligent agent that controls human cognition. Instead, we suggest that converging operations are necessary to determine whether executive actions are responsible for aspects of performance that are intended to measure executive control.

\section{References}

Allport, A., Styles, E. A., \& Hsieh, S. (1994). Shifting intentional set: Exploring the dynamic control of tasks. In C. Umiltà \& M. Moscovitch (Eds.), Attention and performance $X V$ (pp. 421-452). Cambridge MA: MIT Press.

Allport, A., \& Wylie, G. (2000). Selective attention and task set: Activation and inhibition of competing tasks. In S. Monsell \& J. Driver (Eds.),
Attention and performance XVIII (pp. 35-70). Cambridge, MA: MIT Press.

Ashby, F. G. (1982). Testing assumptions of exponential, additive reaction time models. Memory \& Cognition, 10, 125-134.

Ashby, F. G., \& Townsend, J. T. (1980). Decomposing the reaction time distribution: Pure insertion and selective influence revisited. Journal of Mathematical Psychology, 21, 93-123.

Bundesen, C. (1990). A theory of visual attention. Psychological Review, 97, 523-547.

Bundesen, C. (1998a). A computational theory of visual attention. Philosophical Transactions of the Royal Society of London, Series B, 353, 1271-1281.

Bundesen, C. (1998b). Visual selective attention: Outlines of a choice model, a race model, and a computational theory. Visual Cognition, 5, 287-309.

Bundesen, C., \& Harms, L. (1999). Single letter recognition as a function of exposure duration. Psychological Research, 62, 275-279.

Byrne, M. D., \& Anderson, J. R. (2001). Serial models in parallel: The psychological refractory period and perfect time sharing. Psychological Review, 108, 847-869.

Cohen, J. D., Dunbar, K., \& McClelland, J. L. (1990). On the control of automatic processes: A parallel distributed processing account of the Stroop effect. Psychological Review, 97, 332-361.

De Jong, R. (2000). An intention-activation account of residual switch costs. In S. Monsell \& J. Driver (Eds.), Attention and performance XVIII (pp. 357-376). Cambridge, MA: MIT Press.

Gilbert, S., \& Shallice, T. (2002). Task switching: A PDP model. Cognitive Psychology, 44, 193-251.

Goschke, T. (2000). Intentional reconfiguration and involuntary persistence in task set switching. In S. Monsell \& J. Driver (Eds.), Attention and performance XVIII (pp. 331-355). Cambridge, MA: MIT Press.

Jersild, A. T. (1927). Mental set and shift. Archives of Psychology, 14 (Whole No. 89), 5-82.

Kieras, D. E., Meyer, D. E., Ballas, J. A., \& Lauber, E. J. (2000). Modern computational perspectives on executive mental processes and cognitive control: Where to from here? In S. Monsell \& J. Driver (Eds.), Attention and performance XVIII (pp. 681-712). Cambridge, MA: MIT Press.

Logan, G. D. (1985). Executive control of thought and action. Acta Psychologica, 60, 193-210.

Logan, G. D. (1996). The CODE theory of visual attention: An integration of space-based and object-based attention. Psychological Review, 103, 603-649.

Logan, G. D. (2002). An instance theory of attention and memory. Psychological Review, 109, 376-400.

Logan, G. D., \& Bundesen, C. (1996). Spatial effects in the partial report paradigm: A challenge for theories of visual-spatial attention. In D. L. Medin (Ed.), The psychology of learning and motivation (Vol. 35, pp. 243-282). San Diego, CA: Academic Press.

Logan, G. D., \& Gordon, R. D. (2001). Executive control of visual attention in dual-task situations. Psychological Review, 108, 393-434.

Logan, G. D., \& Zbrodoff, N. J. (1982). Constraints on strategy construction in a speeded discrimination task. Journal of Experimental Psychology: Human Perception and Performance, 8, 502-520.

Mayr, U., \& Keele, S. W. (2000). Changing internal constraints on action: The role of backward inhibition. Journal of Experimental Psychology: General, 129, 4-26.

Mayr, U., \& Kliegl, R. (2000). Task-set switching and long-term memory retrieval. Journal of Experimental Psychology: Learning, Memory, and Cognition, 26, 1124-1140.

McGill, W. J. (1963). Stochastic latency mechanisms. In R. D. Luce, R. R. Bush, \& E. Galanter (Eds.), Handbook of mathematical psychology (Vol. 1, pp. 309-360). New York: Wiley.

Meiran, N. (1996). Reconfiguration of processing mode prior to task performance. Journal of Experimental Psychology: Learning, Memory, and Cognition, 22, 1423-1442. 
Meiran, N. (2000). Reconfiguration of stimulus task sets and response task sets during task switching. In S. Monsell \& J. Driver (Eds.), Attention and performance XVIII (pp. 377-399). Cambridge, MA: MIT Press.

Meyer, D. E., \& Kieras, D. E. (1997). A computational theory of executive cognitive processes and multiple-task performance: Part 1. Basic mechanisms. Psychological Review, 104, 3-65.

Norman, D. A., \& Shallice, T. (1986). Attention to action: Willed and automatic control of behaviour. In R. J. Davidson, G. E. Schwartz, \& D. Shapiro (Eds.), Consciousness and self-regulation (Vol. 4, pp. 1-18). New York: Plenum.

Nosofsky, R. M., \& Palmeri, T. J. (1997). An exemplar-based random walk model of speeded classification. Psychological Review, 104, 266-300.

Pfungst, O. (1907). Das Pferd des Herrn von Osten (Der Kluge Hans). Ein Beitrag zur Expreimentallen Tier- und Menschen-Psychologie. Leipzig, Germany: Johann Ambrosius Barth.

Pfungst, O. (1911). Clever Hans (The horse of Mr. Von Osten). A contribution to experimental animal and human psychology (C. L. Rahn, Trans.). New York: Holt.

Rogers, R. D., \& Monsell, S. (1995). The cost of a predictable switch between simple cognitive tasks. Journal of Experimental Psychology: General, 124, 207-231.

Rubinstein, J. S., Meyer, D. E., \& Evans, J. E. (2001). Executive control of cognitive processes in task switching. Journal of Experimental Psychology: Human Perception and Performance, 27, 763-797.

Sohn, M.-H., \& Anderson, J. R. (2001). Task preparation and task repetition: Two-component model of task switching. Journal of Experimental Psychology: General, 130, 764-778.

Spector, A., \& Biederman, I. (1976). Mental set and shift revisited. American Journal of Psychology, 89, 669-679.

Sperling, G., \& Weichselgartner, E. (1995). Episodic theory of the dynamics of spatial attention. Psychological Review, 102, 503-532.

Sudevan, P., \& Taylor, D. A. (1987). The cuing and priming of cognitive operations. Journal of Experimental Psychology: Human Perception and Performance, 13, 89-103.

Townsend, J. T., \& Ashby, F. G. (1983). Stochastic modeling of elementary psychological processes. New York: Cambridge University Press.

Wylie, G. R., \& Allport, D. A. (2000). Task switching and the measurement of "switch costs." Psychological Research, 63, 212-233.

\section{Appendix A}

\section{Interaction Between Repetition and Masking}

\section{Model 1 Interaction Predictions}

Model 1 predicts nonnegative interaction between alternation versus repetition and any factor that prolongs cue-encoding time. In Model 1, the difference in mean RT between alternation and repetition trials is

$$
\begin{aligned}
\mathrm{RT}_{\text {Alternation }}-\mathrm{RT}_{\text {Repetition }}=\mu_{\mathrm{s}} & \cdot\left(\frac{1 / \mu_{\mathrm{c}}}{1 / \mu_{\mathrm{c}}-1 / \mu_{\mathrm{s}}} \exp \left[-\mathrm{SOA} / \mu_{\mathrm{s}}\right]\right. \\
& \left.-\frac{1 / \mu_{\mathrm{s}}}{1 / \mu_{\mathrm{c}}-1 / \mu_{\mathrm{s}}} \exp \left[-\mathrm{SOA} / \mu_{\mathrm{c}}\right]\right) .
\end{aligned}
$$

If $\mathrm{SOA}=0$, this difference is a constant equal to the mean set-switching time, $\mu_{\mathrm{s}}$, independent of the value of the mean cue-encoding time, $\mu_{\mathrm{c}}$. However, if SOA $>0$ and $\mu_{\mathrm{s}}$ is kept constant, then the difference is a monotonic increasing function of the mean cue-encoding time, $\mu_{\mathrm{c}}$.

Proof. To prove that the right-hand side of Equation A1 is a monotonic increasing function of $\mu_{\mathrm{c}}$ for all positive values of $\mu_{\mathrm{c}}, \mu_{\mathrm{s}}$, and SOA, we show that the partial derivative of the right-hand side of Equation A1, with respect to $\mu_{\mathrm{c}}$, is positive for all positive values of $\mu_{\mathrm{c}}, \mu_{\mathrm{s}}$, and SOA (where $\mu_{\mathrm{c}} \neq \mu_{\mathrm{s}}$, so that Equation A1 is meaningful). The partial derivative of the right-hand side of Equation $\mathrm{A} 1$ with respect to $\mu_{\mathrm{c}}$ equals

$$
\begin{aligned}
\left\{\exp \left[-\mathrm{SOA} / \mu_{\mathrm{s}}\right]-[1\right. & +\left(1 / \mu_{\mathrm{c}}\right. \\
& \left.\left.\left.-1 / \mu_{\mathrm{s}}\right) \mathrm{SOA}\right] \exp \left[-\mathrm{SOA} / \mu_{\mathrm{c}}\right]\right\}\left(\frac{1 / \mu_{\mathrm{c}}}{1 / \mu_{\mathrm{c}}-1 / \mu_{\mathrm{s}}}\right)^{2} .
\end{aligned}
$$

This derivative is positive if, and only if,

$$
\left[1+\left(1 / \mu_{\mathrm{c}}-1 / \mu_{\mathrm{s}}\right) \mathrm{SOA}\right] \exp \left[-\mathrm{SOA} / \mu_{\mathrm{c}}\right]<\exp \left[-\mathrm{SOA} / \mu_{\mathrm{s}}\right]
$$

which is equivalent to

$$
1+\left(1 / \mu_{\mathrm{c}}-1 / \mu_{\mathrm{s}}\right) \mathrm{SOA}<\exp \left[\left(1 / \mu_{\mathrm{c}}-1 / \mu_{\mathrm{s}}\right) \mathrm{SOA}\right]
$$

that is,

$$
1+x<\exp (x)
$$

for $x=\left(1 / \mu_{\mathrm{c}}-1 / \mu_{\mathrm{s}}\right)$ SOA. For $x=0$, both $1+x$ and $\exp (x)$ are equal to 1 . But the line $1+x$ is the tangent to $\exp (x)$ at the point $(0,1)$, and $\exp (x)$ is concave upward at every value of $x$, so Equation $\mathrm{A} 2$ is true for all values of $x$ except 0 . Hence, the partial derivative of the right-hand side of Equation A1 with respect to $\mu_{\mathrm{c}}$ is positive for all positive values of $\mu_{\mathrm{c}}, \mu_{\mathrm{s}}$, and SOA, where $\mu_{\mathrm{c}} \neq \mu_{\mathrm{s}}$, Q.E.D.

\section{Model 2 Interaction Predictions}

In Model 2, the difference in mean RT between cue alternation and repetition, $\Delta \mathrm{RT}$, equals

$$
\begin{aligned}
\mathrm{RT}_{\text {Alternation }}-\mathrm{RT}_{\text {Repetition }}=\mu_{\mathrm{a}} \cdot \exp [ & \left.-\mathrm{SOA} / \mu_{\mathrm{a}}\right] \\
& -\mu_{\mathrm{r}} \cdot \exp \left[-\mathrm{SOA} / \mu_{\mathrm{r}}\right] .
\end{aligned}
$$

For SOA $=0$, we get $\Delta \mathrm{RT}=\mu_{\mathrm{a}}-\mu_{\mathrm{r}}$. In Model 2, both $\mu_{\mathrm{a}}$ and $\mu_{\mathrm{r}}$ are increased by masking, and the model is consistent with negative interaction (underadditivity), with null interaction (additivity), and with positive interaction (overadditivity) between masking and alternation versus repetition at $\mathrm{SOA}=0$. The negative interaction at $\mathrm{SOA}=0$ should be found when the effect of masking is greater on $\mu_{\mathrm{r}}$ than on $\mu_{\mathrm{a}}$. Below, we analyze this case and show that the negative interaction diminishes (in absolute value) as SOA increases and that the interaction contrast switches from negative to positive when SOA is sufficiently long.

Consider the general case in which SOA $\geq 0$. Let $\mu_{\mathrm{r}}$ and $\mu_{\mathrm{a}}$ be increasing functions of the level of masking, $m$, with continuous first derivatives $\mathrm{d} \mu_{\mathrm{r}} / \mathrm{d} m$ and $\mathrm{d} \mu_{\mathrm{a}} / \mathrm{d} m$. Thus, $\mathrm{d} \mu_{\mathrm{r}} / \mathrm{d} m>0$ and $\mathrm{d} \mu_{\mathrm{a}} / \mathrm{d} m>0$. Also assume that $\mu_{\mathrm{r}}(m)<\mu_{\mathrm{a}}(m)$ and $\mathrm{d} \mu_{\mathrm{r}} / \mathrm{d} m>\mathrm{d} \mu_{\mathrm{a}} / \mathrm{d} m$ for any given level of masking $m$. $\Delta \mathrm{RT}$ is a function of $m$ and SOA. Let $\partial(\Delta \mathrm{RT}) / \partial m$ denote the partial derivative of $\Delta \mathrm{RT}$ with respect to $m$. The sign of $\partial(\Delta \mathrm{RT}) / \partial m$ equals the sign of the interaction between an infinitesimal increment in masking and alternation versus repetition. Thus, $\partial(\Delta \mathrm{RT}) / \partial m>0$ if the interaction between an increment in masking and alternation versus repetition is positive, provided that the increment is sufficiently small; $\partial(\Delta \mathrm{RT}) / \partial m=0$ if the effects of an increment in masking and alternation versus repetition are additive in the limit as the size of the increment approaches zero; and $\partial(\Delta \mathrm{RT}) / \partial m<0$ if the interaction between an increment in masking and alternation versus repetition is negative provided that the increment is sufficiently small. By Equation A3, 
$\partial(\Delta \mathrm{RT}) / \partial m=\exp \left[-\mathrm{SOA} / \mu_{\mathrm{a}}\right]\left(1+\mathrm{SOA} / \mu_{\mathrm{a}}\right) \mathrm{d} \mu_{\mathrm{a}} / \mathrm{d} m$

$$
-\exp \left[-\mathrm{SOA} / \mu_{\mathrm{r}}\right]\left(1+\mathrm{SOA} / \mu_{\mathrm{r}}\right) \mathrm{d} \mu_{\mathrm{r}} / \mathrm{d} m,
$$

which implies that

$$
\operatorname{Sign}[\partial(\Delta \mathrm{RT}) / \partial m]=\operatorname{Sign}\left[f_{m}(\mathrm{SOA})-\left(\mathrm{d} \mu_{\mathrm{r}} / \mathrm{d} m\right) /\left(\mathrm{d} \mu_{\mathrm{a}} / \mathrm{d} m\right)\right],
$$

where

$$
\begin{aligned}
f_{m}(\mathrm{SOA})=\exp \left[-\mathrm{SOA} / \mu_{\mathrm{a}}\right] & \left(1+\mathrm{SOA} / \mu_{\mathrm{a}}\right) \\
& /\left\{\exp \left[-\mathrm{SOA} / \mu_{\mathrm{r}}\right]\left(1+\mathrm{SOA} / \mu_{\mathrm{r}}\right)\right\} .
\end{aligned}
$$

Thus, the sign of the interaction between a small increment in masking and alternation versus repetition depends on the ratio of $\mathrm{d} \mu_{\mathrm{r}} / \mathrm{d} m$ (i.e., the rate of increase in $\mu_{\mathrm{r}}$ as a function of the level of masking $m$ ) to $\mathrm{d} \mu_{\mathrm{a}} / \mathrm{d} m$ (i.e., the rate of increase in $\mu_{\mathrm{a}}$ with $\left.m\right)$. The interaction is positive if $\left(\mathrm{d} \mu_{\mathrm{r}} / \mathrm{d} m\right) /\left(\mathrm{d} \mu_{\mathrm{a}} /\right.$ $\mathrm{d} m$ ) is smaller than $f_{m}(\mathrm{SOA})$, null if the ratio is equal to $f_{m}(\mathrm{SOA})$, and negative if the ratio is greater than $f_{m}(\mathrm{SOA})$.

By taking the derivative of the right-hand side of Equation A6 with respect to SOA, and using the assumption that $\mu_{\mathrm{a}}>\mu_{\mathrm{r}}$, we find that $\mathrm{d} f_{m}(\mathrm{SOA}) / \mathrm{dSOA}>0$, so $f_{m}(\mathrm{SOA})$ is a monotonic increasing function of SOA. Equation A6 also implies that, as SOA increases from a value of 0 and approaches infinity, $f_{m}(\mathrm{SOA})$ increases from a value of 1 and approaches infinity. Hence, by Equation A5 and the assumption that $\mathrm{d} \mu_{\mathrm{r}} / \mathrm{d} m$ $>\mathrm{d} \mu_{\mathrm{a}} / \mathrm{d} m, \partial(\Delta \mathrm{RT}) / \partial m$ is negative at all SOAs from zero up to a certain critical value $\left(\mathrm{SOA}_{\mathrm{c}}\right)$, null at $\mathrm{SOA}_{\mathrm{c}}$, and positive at all SOAs above $\mathrm{SOA}_{\mathrm{c}}$. Analysis of Equation $\mathrm{A} 4$ shows that $\partial(\Delta \mathrm{RT}) / \partial m$ reaches a maximum at a value of SOA that depends on $\mu_{\mathrm{a}}, \mu_{\mathrm{r}}$, and the ratio between $\mathrm{d} \mu_{\mathrm{r}} / \mathrm{d} m$ and $\mathrm{d} \mu_{\mathrm{a}} / \mathrm{d} m$, and approaches zero from above as SOA tends to infinity.

For any given value of $m$, the critical SOA at which $\partial(\Delta \mathrm{RT}) / \partial m$ crosses zero is uniquely determined by

$$
f_{m}\left(\operatorname{SOA}_{\mathrm{c}}\right)=\left(\mathrm{d} \mu_{\mathrm{r}} / \mathrm{d} m\right) /\left(\mathrm{d} \mu_{\mathrm{a}} / \mathrm{d} m\right),
$$

where

$f_{m}\left(\mathrm{SOA}_{\mathrm{c}}\right)$

$$
=\exp \left[-\mathrm{SOA}_{\mathrm{c}} / \mu_{\mathrm{a}}\right]\left(1+\mathrm{SOA}_{\mathrm{c}} / \mu_{\mathrm{a}}\right) /\left\{\exp \left[-\mathrm{SOA}_{\mathrm{c}} / \mu_{\mathrm{r}}\right]\left(1+\mathrm{SOA}_{\mathrm{c}} / \mu_{\mathrm{r}}\right)\right\}
$$

(cf. Equations $\mathrm{A} 5$ and A6). Thus, $\mathrm{SOA}_{\mathrm{c}}$ is a function of $m$. As $\mu_{\mathrm{a}}, \mu_{\mathrm{c}}$, $\mathrm{d} \mu_{\mathrm{a}} / \mathrm{d} m$, and $\mathrm{d} \mu_{\mathrm{r}} / \mathrm{d} m$ are continuous functions of $m, \mathrm{SOA}_{\mathrm{c}}$ is also a continuous function of $m$.

Let the two levels of masking $(m)$ used in a given experiment be 0 and $M$, respectively. The interaction contrast formed by subtracting the value of $\Delta$ RT for $m=0$ from the value of $\Delta$ RT for $m=M$ can be obtained by integrating $\partial(\Delta \mathrm{RT}) / \partial m$ from $m=0$ to $m=M$. Because $\mathrm{SOA}_{\mathrm{c}}$ is a continuous function of $m$, it has a maximum, $\max \left[\mathrm{SOA}_{\mathrm{c}}\right]$, in the closed interval from 0 up to $M$. For values of SOA greater than $\max \left[\mathrm{SOA}_{\mathrm{c}}\right]$, $\partial(\Delta \mathrm{RT}) / \partial m>0$ at all points in the interval from $m=0$ to $m=M$, so the interaction contrast obtained by the integration must be positive as well. Thus, Model 2 predicts positive interaction at sufficiently long SOAs.

Received December 14, 2001 Revision received October 23, 2002 Accepted October 24, 2002

\section{Low Publication Prices for APA Members and Affiliates}

Keeping you up-to-date. All APA Fellows, Members, Associates, and Student Affiliates receive-as part of their annual dues-subscriptions to the American Psychologist and APA Monitor. High School Teacher and International Affiliates receive subscriptions to the APA Monitor, and they may subscribe to the American Psychologist at a significantly reduced rate. In addition, all Members and Student Affiliates are eligible for savings of up to $60 \%$ (plus a journal credit) on all other APA journals, as well as significant discounts on subscriptions from cooperating societies and publishers (e.g., the American Association for Counseling and Development, Academic Press, and Human Sciences Press).

Essential resources. APA members and affiliates receive special rates for purchases of APA books, including the Publication Manual of the American Psychological Association, and on dozens of new topical books each year.

Other benefits of membership. Membership in APA also provides eligibility for competitive insurance plans, continuing education programs, reduced APA convention fees, and specialty divisions.

More information. Write to American Psychological Association, Membership Services, 750 First Street, NE, Washington, DC 20002-4242. 
Appendix B

Mean Reaction Times and Accuracy Scores for Subjects 1, 2, and 3 in Experiment 1 as Functions of Repetition Condition, Masking, and Stimulus Onset Asynchrony

\begin{tabular}{|c|c|c|c|c|c|c|c|c|}
\hline \multirow[b]{3}{*}{ SOA } & \multicolumn{4}{|c|}{ No mask } & \multicolumn{4}{|c|}{ Mask } \\
\hline & \multicolumn{2}{|c|}{ Repetition } & \multicolumn{2}{|c|}{ Alternation } & \multicolumn{2}{|c|}{ Repetition } & \multicolumn{2}{|c|}{ Alternation } \\
\hline & RT & $\mathrm{P}(\mathrm{C})$ & RT & $\mathrm{P}(\mathrm{C})$ & RT & $\mathrm{P}(\mathrm{C})$ & RT & $\mathrm{P}(\mathrm{C})$ \\
\hline \multicolumn{9}{|c|}{ Subject 1} \\
\hline 0 & 924 & 97 & 1,086 & 96 & 1,069 & 98 & 1,171 & 98 \\
\hline 50 & 871 & 99 & 1,027 & 98 & 1,084 & 99 & 1,089 & 97 \\
\hline 100 & 850 & 100 & 948 & 98 & 964 & 99 & 1,057 & 97 \\
\hline 150 & 775 & 99 & 944 & 98 & 887 & 99 & 983 & 99 \\
\hline 200 & 751 & 100 & 837 & 99 & 909 & 97 & 942 & 99 \\
\hline 250 & 715 & 99 & 848 & 99 & 803 & 98 & 914 & 97 \\
\hline 300 & 701 & 99 & 812 & 99 & 858 & 99 & 891 & 96 \\
\hline 350 & 663 & 98 & 799 & 98 & 761 & 97 & 815 & 99 \\
\hline 400 & 663 & 99 & 753 & 98 & 710 & 98 & 835 & 99 \\
\hline 450 & 671 & 97 & 725 & 98 & 709 & 98 & 756 & 98 \\
\hline 500 & 664 & 99 & 726 & 97 & 704 & 98 & 761 & 99 \\
\hline 550 & 698 & 99 & 716 & 99 & 701 & 98 & 767 & 98 \\
\hline 600 & 642 & 99 & 706 & 99 & 713 & 99 & 725 & 98 \\
\hline 650 & 666 & 99 & 701 & 97 & 672 & 99 & 726 & 98 \\
\hline 700 & 658 & 96 & 705 & 99 & 695 & 98 & 692 & 98 \\
\hline 750 & 630 & 98 & 657 & 99 & 722 & 98 & 721 & 99 \\
\hline 800 & 617 & 98 & 655 & 99 & 660 & 100 & 701 & 99 \\
\hline 850 & 637 & 99 & 671 & 99 & 635 & 99 & 671 & 98 \\
\hline 900 & 604 & 100 & 665 & 99 & 652 & 99 & 639 & 99 \\
\hline 950 & 621 & 99 & 620 & 100 & 613 & 100 & 655 & 98 \\
\hline Mean & 701 & 99 & 780 & 98 & 776 & 99 & 826 & 98 \\
\hline \multicolumn{9}{|c|}{ Subject 2} \\
\hline 0 & 864 & 98 & 909 & 94 & 1,087 & 96 & 1,100 & 94 \\
\hline 50 & 796 & 96 & 872 & 93 & 1,086 & 93 & 1,063 & 94 \\
\hline 100 & 739 & 96 & 816 & 92 & 895 & 96 & 996 & 96 \\
\hline 150 & 680 & 97 & 767 & 97 & 862 & 95 & 910 & 95 \\
\hline 200 & 666 & 97 & 737 & 93 & 813 & 95 & 930 & 97 \\
\hline 250 & 683 & 100 & 735 & 96 & 822 & 92 & 820 & 94 \\
\hline 300 & 602 & 98 & 685 & 97 & 812 & 96 & 840 & 95 \\
\hline 350 & 643 & 99 & 662 & 96 & 780 & 97 & 797 & 95 \\
\hline 400 & 618 & 96 & 671 & 97 & 716 & 93 & 755 & 97 \\
\hline 450 & 614 & 98 & 641 & 97 & 716 & 98 & 749 & 97 \\
\hline 500 & 581 & 97 & 647 & 96 & 690 & 96 & 743 & 98 \\
\hline 550 & 611 & 99 & 633 & 96 & 658 & 97 & 706 & 96 \\
\hline 600 & 599 & 91 & 595 & 95 & 678 & 95 & 668 & 96 \\
\hline 650 & 575 & 99 & 601 & 98 & 629 & 92 & 672 & 96 \\
\hline 700 & 633 & 98 & 583 & 97 & 665 & 99 & 641 & 97 \\
\hline 750 & 570 & 98 & 575 & 95 & 659 & 92 & 675 & 96 \\
\hline 800 & 587 & 96 & 582 & 99 & 637 & 96 & 669 & 96 \\
\hline 850 & 520 & 94 & 585 & 97 & 593 & 93 & 630 & 97 \\
\hline 900 & 529 & 97 & 568 & 96 & 623 & 96 & 670 & 97 \\
\hline 950 & 590 & 97 & 556 & 95 & 630 & 98 & 605 & 98 \\
\hline Mean & 635 & 97 & 671 & 96 & 753 & 95 & 782 & 96 \\
\hline
\end{tabular}


Appendix B (continued)

\begin{tabular}{|c|c|c|c|c|c|c|c|c|}
\hline \multirow[b]{3}{*}{ SOA } & \multicolumn{4}{|c|}{ No mask } & \multicolumn{4}{|c|}{ Mask } \\
\hline & \multicolumn{2}{|c|}{ Repetition } & \multicolumn{2}{|c|}{ Alternation } & \multicolumn{2}{|c|}{ Repetition } & \multicolumn{2}{|c|}{ Alternation } \\
\hline & RT & $\mathrm{P}(\mathrm{C})$ & RT & $\mathrm{P}(\mathrm{C})$ & RT & $\mathrm{P}(\mathrm{C})$ & RT & $\mathrm{P}(\mathrm{C})$ \\
\hline \multicolumn{9}{|c|}{ Subject 3} \\
\hline 0 & 678 & 96 & 730 & 93 & 840 & 98 & 870 & 94 \\
\hline 50 & 604 & 97 & 682 & 95 & 750 & 94 & 812 & 96 \\
\hline 100 & 582 & 98 & 623 & 97 & 700 & 95 & 714 & 96 \\
\hline 150 & 524 & 99 & 570 & 98 & 638 & 97 & 650 & 95 \\
\hline 200 & 502 & 98 & 539 & 97 & 630 & 98 & 604 & 98 \\
\hline 250 & 483 & 96 & 508 & 97 & 576 & 96 & 559 & 97 \\
\hline 300 & 477 & 97 & 492 & 100 & 568 & 98 & 551 & 95 \\
\hline 350 & 474 & 96 & 470 & 95 & 542 & 98 & 530 & 96 \\
\hline 400 & 472 & 98 & 480 & 98 & 542 & 95 & 522 & 97 \\
\hline 450 & 448 & 98 & 469 & 97 & 515 & 96 & 507 & 97 \\
\hline 500 & 472 & 94 & 459 & 97 & 511 & 98 & 495 & 98 \\
\hline 550 & 450 & 98 & 449 & 97 & 480 & 95 & 484 & 97 \\
\hline 600 & 448 & 97 & 461 & 98 & 490 & 97 & 490 & 99 \\
\hline 650 & 443 & 99 & 439 & 97 & 515 & 99 & 465 & 95 \\
\hline 700 & 443 & 98 & 449 & 99 & 492 & 98 & 473 & 99 \\
\hline 750 & 434 & 98 & 432 & 98 & 463 & 97 & 452 & 96 \\
\hline 800 & 429 & 99 & 442 & 96 & 478 & 98 & 461 & 97 \\
\hline 850 & 443 & 98 & 432 & 96 & 452 & 97 & 447 & 96 \\
\hline 900 & 438 & 98 & 429 & 98 & 461 & 97 & 449 & 99 \\
\hline 950 & 430 & 98 & 429 & 96 & 433 & 98 & 435 & 96 \\
\hline Mean & 484 & 98 & 499 & 97 & 554 & 97 & 549 & 97 \\
\hline
\end{tabular}

Note. $\quad \mathrm{SOA}=$ stimulus onset asynchrony $(\mathrm{ms}) ; \mathrm{RT}=$ mean reaction time $(\mathrm{ms}) ; \mathrm{P}(\mathrm{C})=$ percent correct.

Appendix C

Mean Reaction Times and Accuracy Scores as Functions of Repetition Condition, Masking, and Stimulus Onset Asynchrony in Experiment 2

\begin{tabular}{|c|c|c|c|c|c|c|c|c|}
\hline \multirow[b]{3}{*}{ SOA } & \multicolumn{4}{|c|}{ No mask } & \multicolumn{4}{|c|}{ Mask } \\
\hline & \multicolumn{2}{|c|}{ Repetition } & \multicolumn{2}{|c|}{ Alternation } & \multicolumn{2}{|c|}{ Repetition } & \multicolumn{2}{|c|}{ Alternation } \\
\hline & $\mathrm{RT}$ & $\mathrm{P}(\mathrm{C})$ & RT & $\mathrm{P}(\mathrm{C})$ & $\mathrm{RT}$ & $\mathrm{P}(\mathrm{C})$ & $\mathrm{RT}$ & $\mathrm{P}(\mathrm{C})$ \\
\hline 0 & 1,132 & 93 & 1,463 & 92 & 1,465 & 90 & 1,687 & 84 \\
\hline 100 & 976 & 95 & 1,330 & 91 & 1,322 & 91 & 1,577 & 86 \\
\hline 200 & 929 & 95 & 1,237 & 94 & 1,242 & 92 & 1,460 & 88 \\
\hline 300 & 850 & 96 & 1,127 & 91 & 1,142 & 91 & 1,368 & 88 \\
\hline 400 & 820 & 96 & 1,063 & 93 & 1,090 & 93 & 1,266 & 91 \\
\hline 500 & 790 & 97 & 1,013 & 93 & 1,016 & 93 & 1,262 & 90 \\
\hline 600 & 760 & 96 & 995 & 95 & 925 & 94 & 1,139 & 90 \\
\hline 700 & 764 & 97 & 964 & 94 & 912 & 94 & 1,106 & 92 \\
\hline 800 & 769 & 95 & 918 & 94 & 903 & 93 & 1,058 & 91 \\
\hline 900 & 750 & 96 & 917 & 94 & 874 & 92 & 1,020 & 91 \\
\hline Mean & 854 & 96 & 1,103 & 93 & 1,089 & 92 & 1,291 & 89 \\
\hline
\end{tabular}

Note. $\mathrm{SOA}=$ stimulus onset asynchrony $(\mathrm{ms}) ; \mathrm{RT}=$ mean reaction time $(\mathrm{ms}) ; \mathrm{P}(\mathrm{C})=$ percent correct. 


\section{Appendix D}

Mean Reaction Times and Accuracy Scores as Functions of Repetition Condition and Stimulus Onset Asynchrony in Experiment 3

\begin{tabular}{|c|c|c|c|c|c|c|}
\hline \multirow[b]{2}{*}{ SOA } & \multicolumn{2}{|c|}{ Cue repetition } & \multicolumn{2}{|c|}{ Task repetition } & \multicolumn{2}{|c|}{ Task alternation } \\
\hline & RT & $\mathrm{P}(\mathrm{C})$ & $\mathrm{RT}$ & $\mathrm{P}(\mathrm{C})$ & RT & $\mathrm{P}(\mathrm{C})$ \\
\hline 0 & 1,037 & 96 & 1,217 & 95 & 1,240 & 91 \\
\hline 100 & 907 & 95 & 1,135 & 95 & 1,147 & 92 \\
\hline 200 & 790 & 97 & 993 & 95 & 1,062 & 93 \\
\hline 300 & 779 & 97 & 972 & 96 & 982 & 93 \\
\hline 400 & 721 & 96 & 905 & 94 & 935 & 93 \\
\hline 500 & 709 & 97 & 882 & 95 & 937 & 92 \\
\hline 600 & 721 & 96 & 889 & 96 & 906 & 95 \\
\hline 700 & 711 & 97 & 856 & 96 & 911 & 93 \\
\hline 800 & 745 & 96 & 844 & 94 & 861 & 95 \\
\hline 900 & 720 & 97 & 825 & 96 & 888 & 96 \\
\hline Mean & 784 & 96 & 952 & 95 & 987 & 93 \\
\hline
\end{tabular}

Note. $\quad \mathrm{SOA}=$ stimulus onset asynchrony $(\mathrm{ms}) ; \mathrm{RT}=$ mean reaction time $(\mathrm{ms}) ; \mathrm{P}(\mathrm{C})=$ percent correct.

\section{Appendix E}

Mean Reaction Times and Accuracy Scores as Functions of Repetition Condition and Stimulus Onset Asynchrony in Experiment 4

\begin{tabular}{|c|c|c|c|c|c|c|}
\hline \multirow[b]{2}{*}{ SOA } & \multicolumn{2}{|c|}{ Cue repetition } & \multicolumn{2}{|c|}{ Task repetition } & \multicolumn{2}{|c|}{ Task alternation } \\
\hline & $\mathrm{RT}$ & $\mathrm{P}(\mathrm{C})$ & RT & $\mathrm{P}(\mathrm{C})$ & RT & $\mathrm{P}(\mathrm{C})$ \\
\hline 0 & 815 & 97 & 984 & 94 & 1,002 & 94 \\
\hline 100 & 762 & 98 & 889 & 96 & 913 & 93 \\
\hline 200 & 684 & 96 & 823 & 96 & 827 & 94 \\
\hline 300 & 662 & 97 & 758 & 95 & 774 & 95 \\
\hline 400 & 623 & 97 & 728 & 95 & 749 & 96 \\
\hline 500 & 585 & 97 & 692 & 97 & 717 & 95 \\
\hline 600 & 605 & 98 & 659 & 97 & 670 & 95 \\
\hline 700 & 599 & 97 & 659 & 97 & 647 & 96 \\
\hline 800 & 574 & 97 & 635 & 96 & 656 & 95 \\
\hline 900 & 589 & 97 & 621 & 97 & 635 & 96 \\
\hline Mean & 650 & 97 & 745 & 96 & 759 & 95 \\
\hline
\end{tabular}

Note. $\quad \mathrm{SOA}=$ stimulus onset asynchrony $(\mathrm{ms}) ; \mathrm{RT}=$ mean reaction time $(\mathrm{ms}) ; \mathrm{P}(\mathrm{C})=$ percent correct

\section{Appendix F}

Mean Reaction Times and Accuracy Scores as Functions of Repetition Condition, Intertrial Interval, and Stimulus Onset Asynchrony in Experiment 5

\begin{tabular}{|c|c|c|c|c|c|c|c|c|c|c|c|c|}
\hline \multirow[b]{3}{*}{ SOA } & \multicolumn{4}{|c|}{$\mathrm{ITI}=250$} & \multicolumn{4}{|c|}{$\mathrm{ITI}=500$} & \multicolumn{4}{|c|}{$\mathrm{ITI}=1,000$} \\
\hline & \multicolumn{2}{|c|}{ Rep } & \multicolumn{2}{|c|}{ Alt } & \multicolumn{2}{|c|}{ Rep } & \multicolumn{2}{|c|}{ Alt } & \multicolumn{2}{|c|}{ Rep } & \multicolumn{2}{|c|}{ Alt } \\
\hline & RT & $\mathrm{P}(\mathrm{C})$ & RT & $\mathrm{P}(\mathrm{C})$ & RT & $\mathrm{P}(\mathrm{C})$ & RT & $\mathrm{P}(\mathrm{C})$ & RT & $\mathrm{P}(\mathrm{C})$ & RT & $\mathrm{P}(\mathrm{C})$ \\
\hline 0 & 874 & 97 & 1,033 & 93 & 873 & 97 & 1,021 & 92 & 892 & 97 & 987 & 95 \\
\hline 100 & 799 & 97 & 926 & 94 & 765 & 97 & 909 & 96 & 805 & 98 & 901 & 94 \\
\hline 200 & 953 & 97 & 917 & 95 & 739 & 97 & 890 & 96 & 762 & 98 & 865 & 98 \\
\hline 300 & 688 & 98 & 816 & 96 & 703 & 98 & 811 & 96 & 701 & 97 & 789 & 95 \\
\hline 400 & 673 & 97 & 783 & 95 & 706 & 97 & 794 & 96 & 693 & 96 & 746 & 96 \\
\hline 500 & 666 & 97 & 761 & 95 & 671 & 98 & 758 & 97 & 666 & 98 & 722 & 94 \\
\hline 600 & 691 & 97 & 766 & 96 & 686 & 98 & 724 & 97 & 670 & 97 & 726 & 98 \\
\hline 700 & 665 & 98 & 724 & 96 & 676 & 98 & 717 & 96 & 672 & 97 & 703 & 97 \\
\hline 800 & 675 & 97 & 734 & 98 & 661 & 99 & 734 & 96 & 694 & 98 & 725 & 98 \\
\hline 900 & 667 & 98 & 699 & 95 & 655 & 97 & 716 & 97 & 653 & 98 & 705 & 98 \\
\hline Mean & 715 & 97 & 816 & 95 & 714 & 98 & 807 & 96 & 721 & 97 & 787 & 96 \\
\hline
\end{tabular}

Note. $\quad$ ITI $=$ intertrial interval $(\mathrm{ms}) ; \mathrm{Rep}=$ repetition; Alt = alternation; SOA = stimulus onset asynchrony $(\mathrm{ms}) ; \mathrm{RT}=$ mean reaction time $(\mathrm{ms}) ; \mathrm{P}(\mathrm{C})=$ percent correct. 